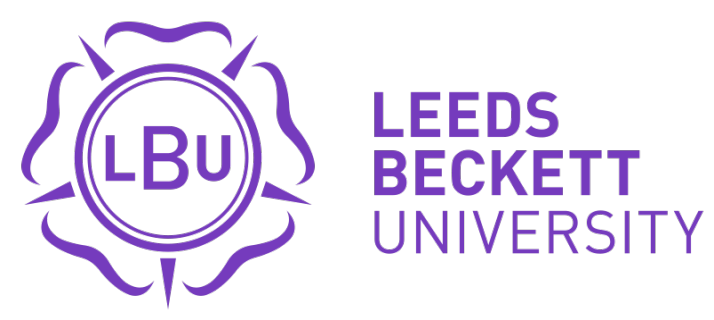

Citation:

Nasir, M and Rizvi, SA and Rossi, M (2018) A treatise on oil price shocks and their implications for the UK financial sector: analysis based on time-varying structural var model. The Manchester School, 86 (5). pp. 586-621. ISSN 1467-9957 DOI: https://doi.org/10.1111/manc.12206

Link to Leeds Beckett Repository record:

https://eprints.leedsbeckett.ac.uk/id/eprint/4572/

Document Version:

Article (Accepted Version)

The aim of the Leeds Beckett Repository is to provide open access to our research, as required by funder policies and permitted by publishers and copyright law.

The Leeds Beckett repository holds a wide range of publications, each of which has been checked for copyright and the relevant embargo period has been applied by the Research Services team.

We operate on a standard take-down policy. If you are the author or publisher of an output and you would like it removed from the repository, please contact us and we will investigate on a case-by-case basis.

Each thesis in the repository has been cleared where necessary by the author for third party copyright. If you would like a thesis to be removed from the repository or believe there is an issue with copyright, please contact us on openaccess@leedsbeckett.ac.uk and we will investigate on a case-by-case basis. 


\title{
A Treatise on Oil Price Shocks \& Their Implications for the UK Financial Sector: Analysis based on Time-Varying Structural VAR Model
}

\author{
Muhammad Ali Nasir ${ }^{1 *}$, Sabih Abass Rizvi*, **Matteo Rossi \\ *Faculty of Business \& Law, Leeds Beckett University \\ **Department of Economic, University of Sannio
}

\begin{abstract}
In this paper, we examined the association among the energy sector stock, oil prices and stock market on the whole. We also considered the UK position from the net oil exporter to net oil importer and implications of the Global Financial Crises. Employing a Time-Varying Vector Auto-regressive (TVSVAR) framework on monthly data from January 1990 to June 2015 in which the sources of time variation were both the coefficients and variance-covariance matrix of the innovations, this study found that historically oil price shocks have negatively affected the stock market, however the energy sector stock has always responded positively holding their title as hedge against oil shocks. It was also found that the shift from net oil exporter to net oil importer did not influence the association between the UK stock market and oil shocks much. Including the discrete break and subsampling of series led to controlling for the prior beliefs and agent's behaviour in the Pre-GFC period. It turned out that the GFC had been a game changer and the stock market as well as the energy sector showed a positive and symmetric response to oil shocks. These findings have profound implications in terms of depressed global aggregate demand and oil shocks dynamics in the Post-GFC world.
\end{abstract}

Keywords: - Financial Markets, Oil Prices Shocks, Energy Sector Stock, Global Financial Crisis, TVSVAR Model

JEL Classification: E44, G11, Q43

1 Corresponding author: Faculty of Business \& Law, Leeds Beckett University, LS1 3HS, UK, m.a.nasir@leedsbeckett.ac.uk Tel; 0044(0)1138123867

Acknowledgment: Authors would like thank Professor Giulio Cifarelli for his kind feedback and comments which led to the improvement and refinement of our work. Moreover, we are also thankful to participants of the World Finance Conference held on July-August 2016 at Saint John's University New York for their kind remarks. 


\section{Introduction \& Background:}

The recent oil price plunge led to the resurgence of the debate on the oil price and its impact on the economic and financial stability. Historically, the oil price hike in 1970s as a market-controlling manoeuvre by the then newly formed Organization of the Petroleum Exporting Countries (OPEC) and the corresponding stock market crash gave birth to the changing dynamics of the oil price and its impact on the financial market as a whole and stock market in particular (Hamilton, 2011). While it is true to say that the oil price is not the sole stability indicator of the stock market, it is repeatedly emphasised as one of the integral ones. Oil prices are a nontrivial determinant of the cost-push inflation, concomitantly; they have implications for monetary policy in terms of its role as an inflation controlling mechanism. Hence, investor's capability to invest is also affected and this, in turn, affects the levels of trading in a stock market, therefore affecting the market as a whole ${ }^{2}$. The dynamics of the stock markets and oils prices in the last couple of years gave a rebirth to debate on connections between the stock performance and oil prices (Stefanova, 2014; Therramus and Austin, 2015). In theory, any event affecting the supply and demand of oil should affect the prices and resultantly its potential impact on the financial sector as petroleum prices have an impact on the national output (Hamilton, 1983). Owing to the geopolitical scenario, the world oil prices saw a huge fall during the first half of the year 2016 and the prices resultantly fell to around the 28 USD per barrel mark. However, in the recent oil price crises, the stock market in the UK has fallen to the 3 years' low in February 2016 down from it's all times high in April 2015 (Financial Times, 2015). While this is a landmark in the UK's equity market, it here creates a question as to how the UK equity market is affected by the global oil price fluctuations. In the analysis of the literature (details next section), it has come to light that there are a number of studies on the effects of oil prices on the economy and also on the stock market, however, there are a few caveats in the existing body of knowledge which this study is aimed to address.

Firstly, there has been limited attention paid to discover the relationship between the oil price shocks and sectoral heterogeneity, specifically, on the relationship between the oil price shocks, UK's stock market and energy sector stock. Perhaps, this investigation in the context of UK is also important in the light of the argument put forward by Park and Ratti (2008) and most lately by Hatemi-J et al (2017), that the impact of oil prices varies country to country. There has been no significant study which has looked at the association between oil price shocks and the stock market in the context of the symmetry of response between the oil sector stock and overall stock market in the UK.

Secondly, the existing studies in the subject area have reported mixed evidence where some hint a positive, while others documented a negative relationship between the stock market and oil price shocks. For instance, in a study by Sadorsky (1999) US stock market have highlighted that the crude oil shocks, result in stock market contractions, whereas the study by and Park and Ratti (2008) on the US and 13 European countries ${ }^{4}$ found heterogeneity in the response of different countries. Their results were complemented by Mohamed's (2011) analysis on the broad European indexes of 12 countries and sectors. Likewise, Ding et al (2016) documented heterogeneity in the response of different stock markets to oil prices shocks while analysing four Asian (Chinese, Hong Kong, Korean, and Japanese) and one in the U.S. stock market. Similarly, Broadstock and Filis (2014) found Chinese

\footnotetext{
${ }^{2}$ Blanchard (2011) linked the inflationary effect with oil prices stating that as the oil prices cause inflation the cost of production increases for the firms, concomitantly there are implications for the monetary policy.

${ }^{3}$ In March 2015 the FTSE-100 index for the first time in its 3-decade history reached to 7000 points (FT, 2015)

${ }^{4}$ Germany, Belgium, Spain, Greece, Sweden, U.K., Finland, Italy, Denmark, Norway, Austria, Netherlands, and France.
} 
stock market more resilient to oil shocks than the US. While, Maghyereh (2004) despite analysing the data of 22 countries could not prove a significant effect of the oil price shocks on the stock market returns, whereas, in a rather more recent case, Nwosa (2014) found a positive effect of oil price shocks on the Nigerian stock market. In a similar fashion, different sectors of the economy and stock market respond differently to the oil shocks. On this aspect, Lee and Ni (2002) and Phan, et al (2016) on US, Zhu et al., (2016) on Chinese, Bouri et al., (2016) on Middle-East, Ftiti et al (2016) on G-7 and Cai et al (2017) on the East Asian countries found significant differences in the response of different sectors to oil shocks. Concomitantly, mixed evidence on the response of different stock markets and different sectors provide a rationale to the subject study to be carried out specifically in the British context.

Thirdly, the existing literature on the association between stock markets and oil shocks also indicates a heterogeneity in the response of stock markets of oil importing and oil exporting countries. Among recent studies, Aloui et al (2012),Demirer et al (2015), Le and Chan (2015), Bouri (2015), Rafiq et al (2016) and Salisu and Isah (2017) found a significant difference in the response of oil exporting and oil importing countries stock markets to oil price shocks. On this aspect, UK is a very interesting case, as we can see in Figure 1, the UK moved from net importer to net exporter in 1980s and then back to a net importer of oil in $2005^{5}$. Hence, it raises the important question of what implications it has in terms of the association between the oil price shocks and UK stock market as well as the energy sector stock.
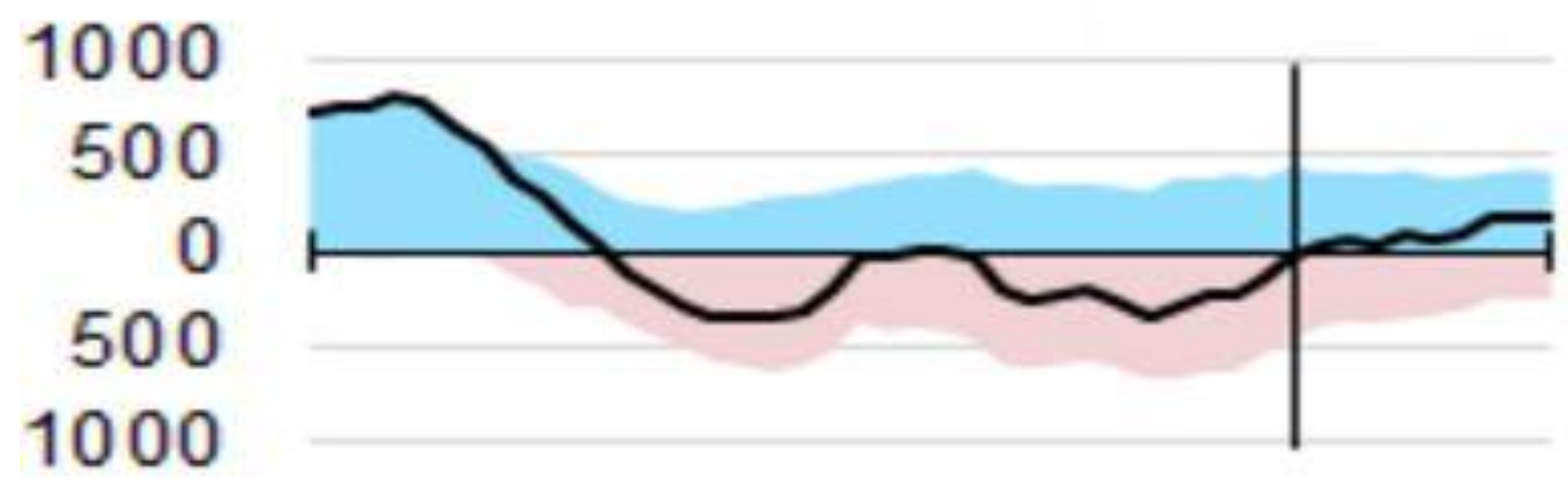

1970

2005

2013

Figure 1: United Kingdom Net Imports of Crude Oil \& Gas (Millions Barrels), Source: UK Department of Energy and Climate Change (2013)

Fourthly, the recent evidence of the nexus between the oil prices and stock market also suggest that there has been a shift in the association due to the Global Financial Crises (2008). Among the recent studies, Du and He (2015), Tsai (2015), Boldanove et al (2016), Kyrtsoua et al (2016) and Zhang (2017) found a shift in the association between the US stock market and oil shocks the after the Global Financial Crises (hereafter GFC). In addition to that, the relationship between the oil prices and the stock market has found to be strongly time-varying by studies like Broadstock and Filis (2014), Inchauspe et al. (2015), Kang et al (2015), Avdulaj and Barunik (2015), Jammazi and Nguyen (2015), Zhu et al (2015), Ghosh and Kanjilal (2016) and Antonakakis et al (2017). Considering this factor as a base to their argument, Liu et al (2015) urged to consider time-varying

\footnotetext{
${ }^{5}$ With the opening of North Sea production, the UK became a significant net exporter of crude oil and gas beginning in the early 1980s, but has been a net importer of gas and oil since 2004 and 2005 respectively.
} 
parameter models while analysing the association between the stock market and oil prices. Therefore, it raises questions whether the association between the oil price shocks and UK stock markets have been changing over time and what implications it could have if we take GFC and oil sector stock into account?

Concomitantly, in terms of contribution to the existing body of knowledge, this study is an important addition to the literature in the subject area as a) we are incorporating the impact on the aggregate stock market while also examining the symmetry of energy sector stock for which we have constructed an index of energy sector firms b) this study is taking into account the UK balance of trade position in oil and its implications for the association among under analysis variables c) we are also taking the Global Financial Crises into account and what implications it has in terms of this study and d) this study is employing a Time Varying Structural Vector Autoregressive (TVSVAR) model to analyse the time varying association among oil price shocks, oil sector stock and stock market.

The paper proceeds as follows, Section 2, provides a brief discussion on the nexus between oil price shocks and the stock market, Section 3 briefly describes the and layouts the empirical framework, Section 4 provides the results of analysis and presentation of findings and Section 5 concludes the argument and discusses implications.

\section{Nexus between Oil Prices \& Stock Market}

The connexion between the oil prices and the stock market is not the matter of association between the two per se, yet it comes from the importance of oil prices for the real economy and resultantly its implications for the financial sector and in the subject case for the stock markets. Among the remarkable contribution on this subject, one can refer to Hamilton (1983, 2005 and 2014), Mork (1989), Dargay and Gately (1995), Hooker (1996), Sadorsky (1999), and most recently Millard and Shakir (2013) investigated the implication of oil prices for UK economy. In a recent study carried out by the PricewaterhouseCoopers UK to analyse the impact of the crude oil price shocks and the British economy, it was reported that if the current drop in the oil price persists over to the year 2020, UK's national output may rise by an additional $1 \%$ annually (PWC, 2015). This brief acknowledgement of the nexus between oil prices and the economy is ample to reflect the importance of the former.

\subsection{Stock Market and Oil Price Shocks}

On the nexus between stock market and oil price shocks, Sadorsky (1999) argued that in the times of increasing petroleum prices, higher inflation might result in higher interest rates and lower investment in an economy leading to lower levels of trading and hence falling stock market indices. Sadorsky (1999) analysis is important in revealing that a) Positive shocks to the oil prices depress real stock returns and b) Oil price shocks have an asymmetric effect on the economy. Similarly, Phan, et al (2016) and Kang et al (2015) reported significant interaction and impact of oil shocks on the covariance of stock return and volatility in the USA. Studies by Arouri et al. (2011) and Bhunia (2012) analysed the same relationship for GCC countries $^{6}$ and India and showed that there exists a relationship between the stock indices and oil price shock which indicates the importance of them and provide rationale to this effort, although their findings showed a difference in terms of direction of causality in different stock markets. Contrarily, at least in terms of statistical significance, despite using data on the 22 developing countries, Maghyereh (2004) could not prove a significant effect of the oil price shocks on the stock market returns in the emerging economies. Similarly, looking

\footnotetext{
${ }^{6}$ Gulf Cooperation Council (GCC) member states are Bahrain, Kuwait, Oman, Qatar, Saudi Arabia and UAE.
} 
through the lens of the future market study by Huang et al. (1996) analysed the impact of the changes in the returns of the oil futures and their relationship with the stock market returns. Against the odds, the results showed no significant association between the oil futures and the equity market returns. Whereas, Nwosa (2014) and Gil-Alana and Yaya (2014) investigation on the stock market in Nigeria revealed that the international crude oil price and the Nigerian stock market have a positive relationship. Contrarily, Kaul and Seyhun (1990) assessed the stock return and oil-related inflation in the US during the OPEC oil crisis period and revealed a significant negative relationship between the oil price shocks and stock returns. Whereas, Kaul and Jones (1996) acknowledging the effect of oil price on the stock market and stock market returns tested the results using the changes in the current and future cash flows. The results revealed that for the Canadian and the US market, the stock market shocks are justified by the strong statistical relationship with the cash flows whereas, for the UK and Japan, the results were not as significant. Their findings are important, as UK stock market seems to behave rather idiosyncratically.

Contributing to the debate on the role of oil prices in explaining the stock returns, a study by Narayan and Gupta (2015) took a deep dive in history by using data on the US stock market and oil prices for over 150 years found the significant predictive power of the oil prices in explaining US stock returns. Similarly, Diaz et al (2016), examines the relationship between oil price volatility and stock returns in the G7 economies (Canada, France, Germany, Italy, Japan, the UK and the US). They found a negative response of G7 stock markets to an increase in oil price volatility. Hence, it brings home to us that the subject nexus varies among countries and inferences drawn from any empirical exercise shall consider this aspect. Nevertheless, a study by Mohamed (2011) focusing on 12 European sector indexes ${ }^{7}$ showed that although there were significant implications of oil prices shocks for volatilities and returns and there was an asymmetry in the response at broad sectoral level. They used the broad indexes while the subject study is focused on the UK and its idiosyncratic features.

\subsection{Country Specific Characteristic; Exporter vs Importers}

The nexus between the oil prices and the stock market might be country specific, perhaps on these lines, Park and Ratti (2008) examined the relationship between the crude price shocks and the stock markets of the US and thirteen European countries. The analysis revealed a strong positive relationship for Norway being an oil exporter, however, for the other countries; the oil price shocks affected the stock returns negatively. In evidence from emerging economies, Aloui et al (2012), analysed the impact of oil prices on the stock market of emerging markets, they reported significant difference among the countries based on their net oil trade position. Focusing on the net oil exporting countries and Gulf Arab stock markets, Demirer et al., (2015) and found that stocks that are more sensitive to oil price changes indeed yield significantly higher returns, suggesting that oil price exposure can serve as a return predictor in these stock markets. Similarly, in a rather comprehensive analysis, Pan et al., (2016) investigated the association between returns of petroleum futures and stock indices in 11 oil-exporting countries and 12 oil-importing countries. They found a significant asymmetric effect in oil-stock relationships. The associations are positive most of the time and are stronger for oil-exporting countries than for oil-importing countries. Hence, it was argued that the stock indices in oil-exporting countries could be better in hedging oil price risk than stock indices in oil-importing countries. However, in another comparative analysis on oil exporting and oil importing countries, Degiannakis et al. (2011) revealed no different results for the oil importing and oil

\footnotetext{
7 Automobile \& Parts, Financials, Food \& Beverages, Oil \& Gas, Health Care, Industrials, Basic Materials, Personal \& Household Goods, Consumer Services, Technology, Telecommunications and Utilities.
} 
exporting countries ${ }^{8}$ and the stock markets showed a unanimous negative response to oil price shocks. While, a study by Le and Chan (2015) attempted to capture the different characteristics of oil refining, exporting and importing. They included Singapore (an oil-refining economy), Malaysia (an oil exporting country) and Japan (an oil-importing economy). The results indicated that the manner in which a stock market reacts to oil price shocks varies between different markets and periods. Perhaps, it depends on differences in the oil characteristics of the economy and the nature of the shock in oil prices. Their findings were complemented by Ding et al., (2016) which investigated the causal relationships between oil shocks and five stock indexes (S\&P 500, Nikkei, Hang Seng, Shanghai, and KOSPI) and reported an asymmetric causality between oil price shocks and different stock markets. In evidence from China (a large importer ), Peng et al (2017) analysis on oil price shocks on Chinese oil companies stock reported lagged spill over effects. Perhaps, the difference can not only be the basis of oil importers and oil exporter countries, as there could be even differences in the responses of stock markets of countries which could be considered as oil importers or oil exporters. On this aspect, Bouri (2015) while analysing the Lebanon, Jordan, Morocco and Tunisia indicated significant differences in the ways the stock markets of these four oil-importing countries react to oil shocks, suggesting a substantial heterogeneity within these oil-importing MENA countries.

\subsection{Sectoral Differences \& Time Variation}

In addition to country-level heterogeneity in the response of the stock market to oil shocks, there is also evidence of sector level heterogeneity. On the sector level analysis, Malik and Ewing (2009) examined the impact of the oil prices on five sectors (financials, industrials, consumers' services, health care, and the technology) in the US indices. The oil market's positive volatility transmission to the sectors was observed highlighting information sharing and "cross-market hedging" to explain the similar behaviour across sectors. However, they did not consider the oil sector stock which the subject study has brought on due to the earlier cited rationale. A Later study by Phan et al (2015) on US stock market also reported a significant difference in the impact of oil shocks on the oil producer and oil consumer firms stocks. In evidence from Spain, Moya-Martínez et al (2014), analysed the impact of oil price shocks on the Spanish stock market and found heterogeneity in different industries response which also changed in different periods. In another study on China, Zhu et al (2015), analysed the effects on oil prices shocks on the Chinese stock market at the industry level, their results revealed that the sensitivity varies across different industries and periods based on structural breaks and asymmetric effects of oil price changes. Later, Zhu et al (2016) revealed that the reaction of market returns to crude oil is highly heterogeneous across the distribution of industry stock return. Xu (2015) reported a significant impact of oil shocks on the UK industry level data. Similarly, Bouri et al (2016), test for causality between world oil prices and sectoral equity returns in Jordan and found that the influence is not uniform across the equity sectors. The oil return shocks significantly affected the financials and the services sectors, while its effect is insignificant on the industrials sector.

In terms of the depth and history of investigations made in the subject area, various sides of the relationship in question have been assessed while leaving room for further research in each case. For instance, Aloui and Jammazi (2012) and Degiannakis (2011) backed the role of petroleum price as a stability driver across the stock markets pointing that in the times of the rapidly increasing and decreasing oil prices, the stock markets are affected negatively. Moreover, Hammoudeh et al. (2009) added that in the times of high petroleum price volatility, the stock risk cannot be hedged against the petroleum prices. Opposing Hammoudeh et al. (2009), Arouri et al. (2011) said that in the times of

\footnotetext{
${ }^{8}$ Canada, Mexico, Brazil, USA, Germany and Netherlands.
} 
petroleum prices, adding oil securities can balance a risky portfolio. In rather recent evidence on the question of whether oil sector is a good diversification tool for stock markets, a study by Avdulaj and Barunik (2015) documented decreasing benefits from diversification over the past ten years. They argued that diversification benefits strongly varied over time. In addition to the Barunik (2015) argument on time variation, Liu et al (2015), while analysing the association between stock returns of S\&P 500 index and oil market variables also argued in favour of considering time-varying association. Similarly, in evidence on the Indian stock market, Ghosh and Kanjilal (2016) found time variation in the impact of international crude oil price on Indian stock market. Similarly, Huang, et al (2016), findings showed that impacts of oil price shocks on the oil-stock nexus differ in the long- and short-terms. There are no significant lead-lag relations between the original oil-stock interaction and its components. Their findings were complemented by Ftiti et al (2016) analysis on the stock markets in the G-7 countries, they reported that the oil price interaction with the stock market was more pronounced in the short and medium term than long term. Similarly, Cai et al (2017) study on the East Asian oil stock which reported that that oil prices and the East Asian stock market move in phase, and oil prices lead to stock returns in the long run. They argued that oil can reduce the risk in the short run, though the degree of risk reduction of oil-stock portfolios decreases over the long term.

On the existing evidence on the Time-variation, employing a Time-varying framework to investigate the association between the oil shocks and the stock market in the United States, Kang et al (2015) reported time variation in the coefficients and impact of shocks. They also found that the impact of shocks have changed during and since GFC, a focal point of subject study as well. In other notable studies on the US, Sim and Zhou (2015) argued the effects of oil price shocks on stock returns are contingent on the performance of the U.S. stock market and magnitude and direction of these shocks. Similarly, Chang and Yu (2013) reported that the impact of oils price shocks on the stock market are regime dependent i.e. varies between turbulent and stable periods. A study by Inchauspe et al. (2015) employing a time-varying coefficients model found that the impact of oil price has become more influential on stock returns since 2007. In evidence from Spain, comparative analysis by MoyaMartínez et al. (2014) suggested that the association between oil price dynamics and stock returns was stronger in during the 2000s than in the 1990s. Jiménez-Rodríguez (2015) investigates nonlinearity in the relationship between oil prices and stock markets and urged on the importance of accounting for the time-varying conditional variability of the oil price shocks. Broadstock and Filis (2014) on China and USA reported that the correlations between oil price shocks and stock returns are time-varying. In evidence form, Gulf Cooperation Countries Jouini (2013) showed a nonlinear long-run relationship between stock markets and oil price changes. Boldanove et al (2016), investigated the time-varying conditional correlation between oil price and stock market volatility for six major oil-importing and oil-exporting countries. They found that the correlation changed over time, furthermore that there were heterogeneities between oil importing and exporting countries, they also found that the correlation changed due to major economic and political events ( $9 / 11$ and GFC). Their findings were complemented by later studies by Antonakakis et al (2017) and Zhang (2017) which argued that the major shocks (Iraq war 2003 and GFC 2008) lead to increase in the correlation between the stock market and oil prices. A study by Jammazi and Nguyen (2015), analysed the impact of oil prices surges on the stock markets of 5 developed countries (USA, UK, Germany, Canada, Japan) reported a regime switching behaviour. Later study by Zhu et al (2017) study on a group of 10 countries (China, India, Japan, South Korea, Brazil, Canada, Mexico, Russia, US, and the UK) also reported regime switching response of stock markets to oil shocks. Importantly results of both studies varied among countries which implying that the regime switching shall be seen in the country context. On this aspect study by Hatemi-J et al (2017) significant differences among the response of stock markets to oil shocks in the US, Japan and Germany. Concomitantly, it lead us to reach a consensus that the oil- 
stock interaction is time-varying and characterized by complexity and nonlinearity making relevant research difficult; this is caused by the intricate components of the entire market from a variety of time horizons. Therefore, the time-varying and heterogeneous influence of the oil shocks on constituents of the stock market at sectoral level is the endeavour of this treatise. Concomitantly, it will have implications in terms of policy as well as in the context of balancing a portfolio with energy sector stock.

\subsection{Global Financial Crisis (GFC)}

The Global Financial Crisis (2008) which is considered as one in a century financial crisis turned out to be a global phenomenon and the contingent spread across the world affecting almost every financial market ${ }^{9}$. There are studies, which suggested that the response of stock market changed in the Post-GFC world. More specifically with respect to the oil shocks, Tsai (2015) investigated that how U.S. stock returns respond differently to oil price shocks prior to, during, and after a financial crisis. They found that the association between the oil shock and the stock market changed in the Post-GFC world. In another study on US stock market, Du and He (2015) revealed that prior to the recent financial crisis, there are positive risk spillovers from the stock market to the crude oil market and negative spillovers from crude oil market to stock market. However, after the financial crisis, bidirectional positive risk spillovers are strengthened markedly. The study by Reboredo and Ugolini (2016) examined the impact of oil price movements on different stock returns. They employ data for three developed economies and the five BRICS countries ${ }^{10}$ and found that the impact of extreme upward and downward oil price changes on upper and lower stock price quintiles was much smaller before compared to after GFC onset. The acknowledged evidence on the oil shock and stock market association in the light of GFC in this section is mostly focused on the US stock market and on the overall market level. However, this study is considering it in the context of UK market as well as oil sector stock by considering a time-varying aspect of under-analysis relationship.

\section{Methodology}

Considering the time-varying association between the stock market and oil shock and supporting evidence (Barunik, 2015 and Liu et al, 2015), we are using a Time-Varying Structural Vector Autoregressive (TVSVAR) model which is based on the seminal work by Primiceri ${ }^{11}$ (2005). The concept of time variation in the multivariate linear framework is fairly well developed for instance studies like Canova (1993), Sims (1993), Stock and Watson (1996) and Cogley and Sargent (2001) estimated VAR models with drifting coefficients, whereas Harvey et al (1994), Kim et al (1998) and Chib et al (2002) considered the multivariate stochastic volatility into models. However, they impose some restrictions on the evolution over time of the elements of the variance-covariance matrix. The covariances do not evolve independently of the variances or a factor structure for the covariance matrix was their typical restrictions. In the later work by Cogley (2003) and Cogley and Sargent (2003) following the same approach used time-varying variances in the context of the VARs with drifting coefficients. However, the simultaneous relations in the under analysis variables in their models were time invariant. Moreover, their analysis was limited to the reduced form models with feasibility only for descriptive analysis of data or forecasting purposes.

\footnotetext{
9 There is consensus that Global Financial Crisis (2008) was the worst financial crisis since 1929s, https://www.imf.org/external/np/sec/pn/2009/pn0997.htm

${ }^{10}$ Developed economies included US, the UK and the European Monetary Union and the BRICS countries i.e. Brazil, Russia, India, China and South Africa.

${ }^{11}$ Please see Primiceri (2005) for an interesting insight into the development of TVSVAR framework.
} 
A later study by Boivin (2001) considered the case of time varying simultaneous relations, but neglected the potential heteroscedasticity of the innovations. Ciccarelli and Rebucci (2003) extend the framework of Boivin (2001) allowing for t-distributed errors, which account for non-persistent changes in the scale of the variances over time. Although, Uhlig (1997) introduced unrestricted multivariate stochastic volatility in the context of VARs,but his model assumed that the VAR coefficients are constant. However, this study uses the TVSVAR framework, where, both the coefficients and the entire variance covariance matrix of the shocks are allowed to vary over time. This is crucial if the objective is distinguishing between changes in the typical size of the exogenous innovations and changes in the transmission mechanism of oil shocks (Primiceri, 2005).

There is also a strand of literature on time variation in linear structures with discrete breaks, for instance, work by Sims, (1999) and Sims and Zha, (2004) with the intention to capture a limited number of switching regimes. Although the discrete break model could be considered as good for the rapid shift in the under analysis entities, it seems less suitable to capture changes in private sector behaviour, where aggregation among agents usually plays the role of smoothing most of the changes (See Primiceri, 2005 for details). In specific to the subject study, the existence of any type of learning dynamics by stock market and the oil price shocks seems to favour a model with smooth and continuous drifting coefficients and heteroscedasticity innovations over a model with discrete breaks. However, in order to get a more inclusive insight, we would consider the period as a whole as well as with the discrete breaks around the points when the UK became a net oil exporter to a net oil importer and around the Global Financial Crisis. Doing so will fill any caveat due to the instrument choice and will provide robustness to our results.

\subsection{The Model}

The TVSVAR model employed in this study has properties of both time-varying coefficients and a time-varying variance-covariance matrix of the additive innovations. It is useful in the sense that drifting coefficients capture possible nonlinearities or temporal variation in the lag structure of the model. Nevertheless, the multivariate stochastic volatility captures the possible heteroscedasticity of the shocks and nonlinearities in the simultaneous relations among the variables of the model. Given that the time variation is allowed both in the coefficients and the variance-covariance matrix, leaves it up to the data to determine whether the time variation of the linear structure derives from changes in the size of the shocks (impulse) or from changes in the propagation mechanism (response). A point to be noted here is that the TVSVAR framework admits many types of shocks (for details see Cogley and Sargent 2003, and Primiceri, 2005). Nevertheless, this feature is in addition to the strategy of having a discrete break, which this study is considering. The model takes the following form:-

$$
\begin{gathered}
\ln \text { FTSE }_{i, t}=\alpha_{10}+\sum_{i=1}^{n} \beta_{1} \ln \text { FTSE }_{t-i}+\sum_{i=1}^{n} \gamma_{1} \ln \text { OilSector }_{t-i}+\sum_{i=1}^{n} \theta_{1} \ln \text { Oil Price }_{t-i}+\varepsilon_{1 i, t}(1) \\
\ln \text { OilSector }_{i, t}=\alpha_{20}+\sum_{i=1}^{n} \beta_{2} \ln \text { FTSE }_{, t-i}+\sum_{i=1}^{n} \gamma_{2} \ln \text { OilSector }_{i, t-i}+\sum_{i=1}^{n} \theta_{2} \ln \text { Oil Price }_{t-i}+\varepsilon_{2 i, t}(2) \\
\ln \text { Oil Price }_{i, t}=\alpha_{30}+\sum_{i=1}^{n} \beta_{3} \ln \text { FTSE }_{t-i}+\sum_{i=1}^{n} \gamma_{3} \text { OilSector }_{t-i}+\sum_{i=1}^{n} \theta_{3} \ln \text { Oil Price }_{t-i}+\varepsilon_{3 i, t}(3) \\
\varepsilon_{t} \sim \mathrm{N}(0, \sigma 2),
\end{gathered}
$$




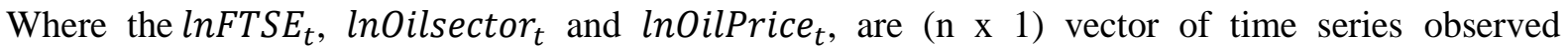
endogenous variables, $a_{10}, a_{20}$ and $a_{30}$ are (nx1) vector of time varying coefficients that multiply constant terms; $\beta_{i}, \gamma_{i}$ and $\theta i$ are the ( $\mathrm{n} \times \mathrm{n}$ ) matrixes of time varying coefficients, and $\varepsilon_{i}$ are the heteroscedastic unobservable shocks with variance covariance matrix $\Omega_{t}$. Without the loss of generality, if we consider the triangular reduction of covariance matrix $\Omega_{t}$, it can be defined as

$$
A_{t} \Omega_{t} A_{t}^{\prime}=\sum_{t} \sum_{t}^{\prime}
$$

Where $A_{t}$ is the lower triangular matrix

$$
A_{t}=\left[\begin{array}{cccc}
1 & 0 & 0 & 0 \\
a_{10} & 1 & 0 & 0 \\
a_{20} & \beta_{2 i} & 1 & 0 \\
a_{30} & \beta_{3 i} & \gamma_{3 i} & 1
\end{array}\right]
$$

And $\sum_{t}$ is the diagonal matrix

$$
\sum_{t}=\left[\begin{array}{cccc}
\sigma_{1, t} & 0 & 0 & 0 \\
0 & \sigma_{2, t} & 0 & 0 \\
0 & 0 & \sigma_{3, t} & 0 \\
0 & 0 & 0 & \sigma_{4, t}
\end{array}\right]
$$

Thus, it follows that the equation 1 to 3 can be modified to

$\operatorname{lnFTSE}_{i t}=a_{10}+\sum_{i=1}^{n} \beta_{1} \ln$ FTSE $_{t-i}+\sum_{i=1}^{n} \gamma_{1} \ln$ OilSector $_{t-i}+\sum_{i=1}^{n} \theta_{1} \ln$ Oil Pr ice $_{t-i}+A_{t}^{-1} \sum_{t} \varepsilon_{t}(5)$

$\ln$ OilSector $_{i, t}=\alpha_{20}+\sum_{i=1}^{n} \beta_{2} \ln$ FTSE $_{, t-i}+\sum_{i=1}^{n} \gamma_{2} \ln$ OilSector $_{i, t-i}+\sum_{i=1}^{n} \theta_{2} \ln$ Oil Pr ice $_{, t-i}+A_{t}^{-1} \Sigma_{t} \varepsilon_{t}(6)$

$\ln {\text { Oil Pr } \text { ice }_{i, t}}_{=}=\alpha_{30}+\sum_{i=1}^{n} \beta_{3} \ln$ FTSE $_{, t-i}+\sum_{i=1}^{n} \gamma_{3}$ OilSector $_{t-i}+\sum_{i=1}^{n} \theta_{3} \ln$ Oil Pr ice $_{t-i} A_{t}^{-1} \sum_{t} \varepsilon_{t}(7)$

$$
V\left(\varepsilon_{t}\right)=I_{n}
$$

Stacking in a vector say $\beta_{t}$ all the $\beta_{1,2 \& 3}$ coefficients the equations (5-7) can be re-written as;-

$$
y_{t}=X_{t}^{\prime} B_{t}+A_{t}^{-1} \sum_{t} \varepsilon_{t},
$$

Where $y_{t}$ is the nx1 vector of observed endogens variable in each case, the equation 8 can be re-written as

$$
X_{t}^{\prime}=I_{n} \otimes\left[1, y_{t-1}^{\prime}, \ldots, y_{t-k}^{\prime}\right]
$$


Where the symbol $\otimes$ denotes the Kronecker product. It is common to decompose the variancecovariance matrix as resulted in the equation $(8)^{12}$. In specific to the time-varying VAR models, studies e.g. Cogley (2003) and Cogley and Sargent (2003) have a similar decomposition, but with a time invariant $A_{t}$ matrix. However as discussed earlier, it is vital that to allow the matrix $A_{t}$ to vary over time for a time varying structural VAR framework. Keeping the $A_{t}$ constant would imply that an innovation to the $i-t h$ variable has a time invariant effect on the $j-t h$ variable. This is clearly undesirable if one is aiming to model the time variation in a simultaneous equation model, where simultaneous interactions among variables are fundamental as in this treatise.

Now if we let the $a_{t}$ be the vector of non-zero and non-one elements of the matrix $A_{t}$ and $\sigma_{t}$ be the vector of the diagonal element $\mathrm{s}$ of the matrix $\sum_{t}$. We can specify the dynamics of our model's time varying parameter as below:-

$$
\begin{aligned}
& B_{t}=B_{t-1}+v_{t}, \\
& a_{t}=a_{t-1}+\zeta_{t}, \\
& \log \sigma_{t}=\log \sigma_{t-1}+\eta_{t},
\end{aligned}
$$

Where the elements of the vector $B_{t}$ are modeled as random walks, as well as the free elements of the matrix $A_{t} \cdot{ }^{13}$ All the innovations in the model are assumed to be jointly normally distributed with the following assumptions on the variance covariance matrix:

$$
V=\operatorname{Var}\left(\left[\begin{array}{c}
\varepsilon_{t} \\
v_{t} \\
\zeta_{t} \\
\eta_{t}
\end{array}\right]\right)=\left[\begin{array}{cccc}
I_{n} & 0 & 0 & 0 \\
0 & Q & 0 & 0 \\
0 & 0 & S & 0 \\
0 & 0 & 0 & W
\end{array}\right]
$$

Where $I_{n}$ is a n n-dimensional identity matrix, $Q, S$ and $W$ are positive definite matrices ${ }^{14}$. The coefficients of the contemporaneous relations among variables are assumed to evolve independently in each equation, although it is not crucial assumption, yet it simplifies the inference and increases the efficiency of the estimation algorithm.

\subsection{Bayesian Estimation:}

The estimation of model is carried out using the Bayesian method which will be used to evaluate the posterior distribution of the parameters of interest, in specific to our case $B^{T} A^{T} \Sigma^{T}$ and the hyperparameters of the variance covariance matix $V$. The Bayesian is an appropriate approach in a

\footnotetext{
12 It is particularly common in the studies focused on the problem of efficiently estimating covariance matrices (see, Smith and Kohn, 2002 or/and) Primiceri, 2005).

13 The standard deviations $\sigma_{t}$ are assumed to evolve as geometric random walks and classed as stochastic volatility.

${ }^{14} \mathrm{~A}$ to note here is that none of restrictions on the structure of $\mathrm{V}$ are essential as all the zero blocks could be substituted by non-zero blocks, with only small modifications of the estimation procedure. Nevertheless, there are at least two reasons suggesting a choice of $\mathrm{V}$ as the one described in (13). The first one is related to the already high number of parameters of the model. Adding all the off diagonal elements of $\mathrm{V}$ would require the specification of a sensible prior, able to prevent cases of ill-determined parameters. The second reason is that allowing for a completely generic correlation structure among different sources of uncertainty would preclude any structural interpretation of the innovations.
} 
scenario where the distinction between parameters and shocks is less clear while one is dealing with unobservable components. In additions to that there are three reasons to choose and prefer Bayesian over classical estimation to estimate subject class models, a) in case, the variance of the time varying coefficients is small, the classical maximum likelihood estimator of this variance has a point mass at zero, related to the commonly called pile-up problem, b) classical maximum likelihood is related to the high dimensionality and nonlinearity of the problem which is a problem as such a complicated model often has a likelihood with multiple peaks, some of which is uninteresting or implausible regions of the parameter space. Moreover, if these peaks are very narrow, the likelihood may reach particularly high values, not at all representative of the model's fit on a wider and more interesting parameter region. In a Bayesian setting, the use of uninformative priors on reasonable regions of the parameter space is nevertheless effective in ruling out these misbehaviours c) Practicality, although it is in principle possible to write up the likelihood of the model, it is a hard task to maximize it over such a high dimensional space. Bayesian methods deal efficiently with the high dimension of the parameter space and the nonlinearities of the model, splitting the original estimation problem into smaller and simpler ones. Concomitantly, Bayesian seems appropriate approach to consider. Furthermore, we are using Gibbs sampling for the posterior numerical evaluation of the parameters of interest. It is a particular variant of the Markov chain Monte Carlo (MCMC) methods that consists of drawing from lower dimensional conditional posteriors as opposed to the high dimensional joint posterior of the whole parameter set. As the MCMC is a smoothing method and therefore delivers smoothed estimates, i.e. estimates of the parameters of interest based on the entire available set of data. The smoothed estimates are more efficient and hence preferable, particularly in a study like this where the objective is an investigation of the true evolution of the unobservable states over time (See Primiceri, 2005 for detailed discussion).

\subsection{Prior selection}

The selection of prior distributions is based on their appropriateness and applicability. To start with, the assumption that the initial states for the coefficients, for the covariances, for the log volatilities and the hyperparameters are independent of each other is initiative. The priors for the hyperparameters, $Q, W$ and the blocks of $\mathrm{S}$, are assumed to be distributed as independent inverseWishart. The priors for the initial states of the time varying coefficients, simultaneous relations and $\log$ standard errors $p\left(B_{0}\right), p\left(a_{0}\right)$, and $p\left(\log _{\sigma 0}\right)$, are assumed to be normally distributed. These assumptions together with (10), (11) and (12) imply normal priors on the entire sequences of the B's, $\alpha$ 's and $\log \sigma$ 's (conditional on $\mathrm{Q}, \mathrm{W}$ and $\mathrm{S}$ ).

As mentioned earlier, the MCMC algorithm is used to generate a sample from the joint posterior of $B^{T} A^{T} \Sigma^{T}$ and $V$. The Gibbs sampling is used in order to exploit the blocking structure of the unknowns and it is performed in four steps, a) drawing in turn time varying coefficients $B^{T}, b$ ) simultaneous relations $A^{T}$, c) volatilities $\Sigma^{T}$ and d) hyperparameters $V$, conditional on the observed data and the rest of the parameters ${ }^{15}$. The empirical framework discussed in paragraphs above is applied on the data. The details of dataset are as follows:-

3.5 Data: The data used in this study includes the Brent crude oil price which has been chosen, as it is the benchmark for the majority of oil traded globally and imported into the United Kingdom. In addition to the FTSE-All Share Index and the average Energy Sector share prices have been added to shape the analysis. The figures for the oil price were taken from US Energy Information Administration database while the share prices were from the Financial Times database. The data

${ }^{15}$ For details on identification and structural interpretation, please see Primiceri, 2005. 
selected ranges from January 1990 to June 2015 to incorporate in our analysis an extended period of time, which includes positive and negative oil price shocks over time while making the use of the latest figures available to ensure that the study is up to date and takes the recent developments into account. The spans over 25 years and 306 observations. The reason for this choice is to use data of reasonably long period and up to the latest observations. In terms of shocks, although study by Kilian (2009) disentangled the demand and supply shock in crude market to show their differences, however this aspect will be captured in our framework in which the time-varying parameters of associations drift smoothly incorporating demand as well as the supply shocks into account, furthermore, as we will draw the impulses at different times it is possible in this framework to identify the origin of shock i.e. whether is it demand pull or cost push, however doing would be beyond the scope of this inquiry although the framework has accounted for it by looking at the periods like GFC and next export position of UK. The model will be estimated on the whole dataset in the first phase and thereafter we will introduce the discrete breaks. In order to do so, following the Tsai (2015) and Reboredo and Ugolini (2016) practice, we divided the data into subsamples. The pre-financial crisis period is chosen from 1990 to August 2008. The post crises period is from October 2008 to June 2015. As Reboredo and Ugolini (2016) argued, there is no real consensus on the date of onset of the global financial crisis. However, as the September 2008, coinciding with the collapse of Lehman Brothers that almost brought down the world's financial system; we used this month as a break point even though the foundations of the crisis were forged prior to this date. The data set as described is classified as the following variables:

Brent Crude Oil Price: The monthly price of the Brent crude oil has been taken from Energy Information Administration, a US database for energy statistics.

FTSE All-Share Index: The index values for the FTSE all-share index of the London Stock Exchange has been sourced from the Financial Times.

Average Oil Sector Price: The Average Oil Sector price is calculated as a weighted monthly average of the oil sector companies in the FTSE all-share index. This represents mainly twelve stocks of eleven different companies. The average price was calculated every month for the number of registered companies with the last company added to the energy index of the FTSE all share in June 2010 named Ophir Energy. Other companies include British Petroleum, British Gas, Cairn Energy, Premier Oil, SOCO International, Tullow Oil, Enqeust PLC, Exillion Energy, Nostrum Oil, Shell-A and Shell-B. An important point to note here is that although the oil companies are part of FTSE All-shares the measure we constructed i.e. average oil sector stock prices is different in composition as the former is based on the capitalisation-weighted index of over 600 companies, while is the latter is based on the just 11 companies. Nonetheless, in terms of the capitalisation which is the base of index weightage of the All Share Index, the constituents of oil sector are not comparable with the major companies in all market. It is explicit in the fact that only two companies (B.P and Shell) hold a place in the FTSE-100 index. Concomitantly, for the inconclusiveness and to incorporate the whole market as it is the theme of this study, we employed the All Share Index.

\section{Analysis and Findings}

Prior to the application of TVSVAR framework, we conducted a couple of tests to gain an insight into the statistical properties of under analysis time series. Now, an important and interesting aspect of the Bayesian approach is that it is not dependent on the requirement of stationarity as seminal work by 
Sims (1989) and Fanchon and Wendel (1992) suggested that no assumptions of stationarity is required to be imposed under the Bayesian framework. However, we still performed the Unit root tests to get insight into the data and see if there has been any explosive behaviour or major issues with the data series. ${ }^{16}$ The Augmented Dickey-Fuller test is applied to test the stationarity in the presence of break with both Additive Outliers (AO) and Innovative Outliers (IO) as defined by the seminal work by Fox (1972) and later by Tsay (1988) ${ }^{17}$. The results are displayed in the Table-1 below;-

Table 1 : ADF Test with Break: Additive \& Innovative Outliers

\begin{tabular}{|c|c|c|c|c|c|}
\hline \multirow{4}{*}{ Level } & Variable & $\begin{array}{l}\text { ADF Test } \\
\text { Statistic }\end{array}$ & $\begin{array}{c}\text { Critical Value } \\
\text { at } 1 \% \text { level }\end{array}$ & $\begin{array}{c}\text { Critical Value } \\
\text { at } 5 \% \text { level }\end{array}$ & ${ }^{* * *}$ Probability \\
\hline & FTSE & -3.934 & -5.711 & -5.155 & 0.487 \\
\hline & Oil Price & -4.264 & -5.711 & -5.155 & 0.315 \\
\hline & Avg. Energy Sector & -2.021 & -5.711 & -5.155 & 0.978 \\
\hline \multirow[t]{3}{*}{ 1st Difference } & FTSE & -16.394 & -5.711 & -5.155 & $0.001^{*}$ \\
\hline & Oil Price & -13.369 & -5.711 & -5.155 & $0.001 *$ \\
\hline & Avg. Energy Sector & -18.794 & -5.711 & -5.155 & $0.001 *$ \\
\hline
\end{tabular}

The results showed that the all the series have a unit root when tested at the level as the ADF test statistic with the structural break was lower than the critical value at $5 \%$ level ${ }^{18}$. However, the data found to be stationary at $1^{\text {st }}$ difference ${ }^{19}$. Concomitantly, all the series at integrated of order I (1) which implies there was not much to worry in terms of series behaviour. Secondly, to determine an

\footnotetext{
${ }^{16}$ As a choice of method, we used the Augmented Dickey-Fuller (ADF) with a structural break which is preferable than the simple ADF test based on the seminal work by Dickey and Fuller (1979). On this aspect, Perron (1989) cautioned that ADF test could give biased results. The critique by Perron (1989) lead to the development of a large literature outlining various unit root tests that remain valid in the presence of a break (see Hansen, (2001) and Perron (2006) for discussion). On theoretical grounds, a very important point we must elaborate here is that the stock market and oil prices data series exhibit a structural change from their usual trend due to various reasons, for instance, macroeconomic policy decisions or financial and economic events. Making this point as a base, some studies like Ranganathan and Ananthakumar (2010) criticised that ADF test is biased towards null of random walk in presence of such a structural break in a series. The reason was given that in case of not accounting for a structural break, the random shocks are assumed to have a permanent effect on the system. Concomitantly, this study is considering the aspect of structural breaks in the series. To start with, all series are transformed to their natural logs. The date of the break was endogenously determined by using the data employed rather a given date. We choose the date with the strongest evidence of a break. The alternative minimize and maximize options are provided to allow for evaluation of one-sided alternatives, and will produce different critical values for the final Dickey-Fuller test statistic and tests with greater power than the nondirectional alternatives. This practice is supported by the seminal work by Zivot and Andrews (1992), Banerjee et al., (1992) and Vogelsang and Perron (1998).

${ }^{17}$ It appears that Fox (1972) is the first to consider outliers within time series, assuming an AR structure with Gaussian noise. Two broad categories of outlier are defined: "Additive Outliers (AO)" where a single point is affected and "Innovative Outliers (IO)" where an innovation to the process affects both an observation and the subsequent series. Fox's approach is basically a likelihood ratio criteria, comparing the estimated error for an observation with the estimated standard error of that discrepancy.

${ }^{18}$ The stationarity is presumed where the test statistic value is greater than the critical value in the absolute terms and the probability of occurrence is below 0.05 significance value. Where the variable fails the above criterion, it is then tested at the first difference and so on as advised in the test guidelines by Dickey and Fuller (1979). The number of lags in the ADF test are based on the Schwarz information criterion (SIC) has it is considered a best criteria in the presence of structural breaks (See Asghar and Abid (2007)

19 It is common to work in differenced measures of returns, however the order or integration among the variables shall be same, given that we are employing the Bayesian estimation the differencing is not required for stationarity, although doing so may accompanied the cost of information loss (see Hendry, 1995 Reiss (2015), hence we stick to the log level data.
} 
appropriate lag length we performed lag length section test using alternative information criteras (Akaike Information Criterion, Schwarz Information Criterion, Hannan-Quinn Information Criterion). All the lag selection criteria unanimously suggested two as optimal numbers of lags which are then incorporated into the analysis ${ }^{20}$. Lastly, we performed a co-integration test using Johansen method. A point to acknowledge here which may arise is that the Johansen identification procedure makes use of the observed data and therefore is not required under a pure Bayesian scheme. However, Engle and Yoo (1987) also argued that the Bayesian estimation is not appropriate for the co-integrated data because the standard prior imply a model that approaches the classical VAR model estimated with the differenced data. Furthermore, the model can be misspecified because it does not include error correction term, although, seminal work by Fanchon and Wendel (1992) showed that the Bayesian models are useful even in the case of nonstationarity and cointegration (see Fanchon and Wendel, 1992 for a detailed discussion $)^{21}$. However, for the sake of presentation, the convenience of the reader and to fade the fear of Engle and Yoo (1987), we performed and presented the Johansen Cointegration tests to see if the variables are co-integrated. To start with, we apply the Johansen test which with the assumption of a linear deterministic trend in the data. It reveals the following: -

Table 2 : Johansen Cointegration Test; Trace and Max-Eigen Value Stats.

\begin{tabular}{|c|c|c|c|c|c|c|}
\hline & \multicolumn{3}{|c|}{ Trace Test at 5\% } & \multicolumn{3}{|c|}{ Max-Eigen Value at 5\% } \\
\hline $\begin{array}{l}\text { Hypothesized } \\
\text { No. of CE(s) }\end{array}$ & $\begin{array}{c}\text { Trace } \\
\text { Statistic }\end{array}$ & Critical Value & Prob.** & $\begin{array}{l}\text { Eigenvalue } \\
\text { Statistic }\end{array}$ & $\begin{array}{l}\text { Critical } \\
\text { Value }\end{array}$ & Probe. ** \\
\hline None & 20.2560 & 29.7971 & 0.4057 & 12.7863 & 21.1316 & 0.4721 \\
\hline At most 1 & 7.4697 & 15.4947 & 0.5237 & 5.5301 & 14.2646 & 0.6739 \\
\hline At most 2 & 1.9396 & 3.8415 & 0.1637 & 1.9396 & 3.8415 & 0.1637 \\
\hline
\end{tabular}

Trace test and Unrestricted Rank Test (Max-Eigenvalue) indicates no co-integration at the 5\% level **MacKinnon-Haug-Michelis (1999) p-values

The results summarised in Table 2 showed that the null of no cointegration cannot be rejected at a statistical level of significance ( $p$-value $<0.05$ ) according to both Trace and Max-Eigen values criteria. Thereafter, we used alternative scenarios with the assumption of no trend or linear quadratic trend in data with a rationale to check the robustness of results. However, in each case, the null of no cointegration could not be rejected at a statistical level of significance ${ }^{22}$. Hence, we can proceed to our TVSVAR model and Bayesian estimation without any issues raised by Engle and Yoo (1978).

\subsection{Time Varying Structural Vector Auto-Regression (TVSVAR) Model}

The sample runs from January 1990 to June 2015. There are two lags included in the model and simulations carried out by 10000 iterations of the Gibbs sampler with 2000 are discarded (burned in draws) for convergence. The convergence checks were stationary and the autocorrelation functions of the draws decay quite fast. The first 40 observations i.e. three years and a quarter (January 1990 to April 1994) were used to calibrate the prior distribution. For instance, the mean and variance of $B_{0}$ are chosen to be the OLS point estimates $\hat{B}_{\mathrm{OLS}}$ and 4 times its variance in a time invariant VAR, which is estimated by using the initial subsample. In the similar fashion, priors are obtained for $A_{t}$ whereas for

\footnotetext{
${ }^{20}$ To conserve the space the results are not presented here and are available on request.

${ }^{21}$ Moreover, as the full rank matrix used in these operations is arbitrary, the individual parameters of the cointegration relations and the weights are not uniquely determined without making some further assumptions. However, the Johansen procedure ensures that all the parameters of the co-integrated VAR are identified (Warne, 2006).

${ }^{22}$ Results of the Johanson co-integration test with alternative assumptions are available on request.
} 
$\sigma_{t}$ the mean of the distribution if chosen to be the logarithm of the OLS estimates of the standard errors of the same time invariant VAR, whereas the variance covariance matrix is assumed to be the identity matrix. Lastly, the scale matrices and degree of freedom are required for the inverse-Wishart prior distributions of the hyperparameters. We choose to set the degrees of freedom to 4 for $\mathrm{W}$ and 2 and 3 for the two blocks of S (actually, it is one plus the dimension of each matrix). For the inverseWishart distribution to be appropriate the degrees of freedom must exceed the dimension respectively of $\mathrm{W}$ and the blocks of $\mathrm{S}$, due to this reason we choose the degrees of freedom differently. For $\mathrm{Q}$ we choose to set the degrees of freedom 40 as it is the size of the initial subsample. This is due to the reason that a bit tighter prior seems to be necessary in order to avoid implausible behaviours of the time varying coefficients (Primiceri 2005). Concomitantly, the scale matrices $\bar{Q}, \bar{W}, \overline{S_{1}}$ and $\overline{S_{2}}$ are chosen to be constant fractions of the variances of the corresponding OLS estimates on the initial subsample (multiplied by the degrees of freedom, because, in the inverse-Wishart distribution, the scale matrix has the interpretation of sum of squared residuals). This is in line with the (Cogley, 2003 and Primiceri 2005). If we summarise, the priors take the form:-

$$
\begin{gathered}
B_{0} \sim N\left(\hat{B}_{\mathrm{OLS}}, 4 . \mathrm{V}\left(\hat{B}_{\mathrm{OLS}}\right)\right), \\
A_{0} \sim N\left(\hat{A}_{\mathrm{OLS}}, 4 . \mathrm{V}\left(\hat{A}_{\mathrm{OLS}}\right)\right), \\
\log \sigma_{0} \sim N\left(\log \hat{\sigma}_{\mathrm{OLS}}, I_{n}\right), \\
Q \sim I W\left(K_{Q}^{2} \cdot 40 . \mathrm{V}\left(\hat{B}_{\mathrm{OLS}}\right), 40\right), \\
W \sim I W\left(K_{w}^{2} \cdot 4 . I_{n}, 4\right), \\
S_{1} \sim I W\left(K_{s}^{2} \cdot 2 . \mathrm{V}\left(\widehat{A_{1}}, \mathrm{OLS}\right), 2\right), \\
S_{2} \sim I W\left(K_{s}^{2} .3 . \mathrm{V}\left(\widehat{A_{2}}, \mathrm{OLS}\right), 3\right),
\end{gathered}
$$

Where $S_{1}$ and $S_{2}$ denote the two blocks of S, while $\widehat{A_{1}}$, oLs and $\widehat{A_{2}}$, oLs are the two correspondent blocks of $\hat{A}_{\text {OLS. }}$. The benchmark results are obtained using the following values $K_{Q}=0.01, K_{S}=0.1, K_{W}=0.01$. In this setting, the priors are not flat; however, they are diffuse and uninformative. We did choose alternative prior specification to test the robustness of results. The empirical results starts with the analysis of time variation of the oil price shocks.

\subsection{Oil Price Shocks.}

In terms of ordering of the variables the oil prices are ordered last, it is due to the exogenous nature of oil price shocks, specifically, in the context of the subject study. Moreover, the identification assumption also implies that oil shocks affect with lags. The simultaneous interaction between FTSE All shares and energy sector stock is arbitrarily modelled in a lower triangular form with FTSE All Shares first. It is not an identification condition but for the sake of normalization, although the arbitrary normalisation may have potential to make difference, in this setting the ordering of the stock market block did not affect the results. To start with, it is important to have a look at the time varying stranded deviation of the of the oil price shocks. The Figure $2(\mathrm{a}-\mathrm{c})$ presents the plot of the posterior mean and the $16^{\text {th }}$ and $84^{\text {th }}$ percentiles of the time varying standard deviation of the oil price shocks. The percentiles cross-ponds to the bound of a one standard deviation confidence interval. 
The graph gives some interesting insight as the periods of the late 1990s and 2008 exhibits a substantially higher variance of oil price shocks. It is not a surprising and quite intuitive outcome as firstly, those periods correspond to the periods of high volatility in the oil prices, the oil prices fell from over \$ 70 in September 1990 to under \$17 in November 1998, before taking many twist and turns. Secondly, Global Financial Crises (2008) also showed a high period of volatility (EIA, 2016). Interestingly, it is also obvious in the Figure $2(\mathrm{a} \& \mathrm{~b})$ that the FTSE All Shares and Oil Sector Stock have a rather volatile behaviour around these periods ${ }^{23}$.

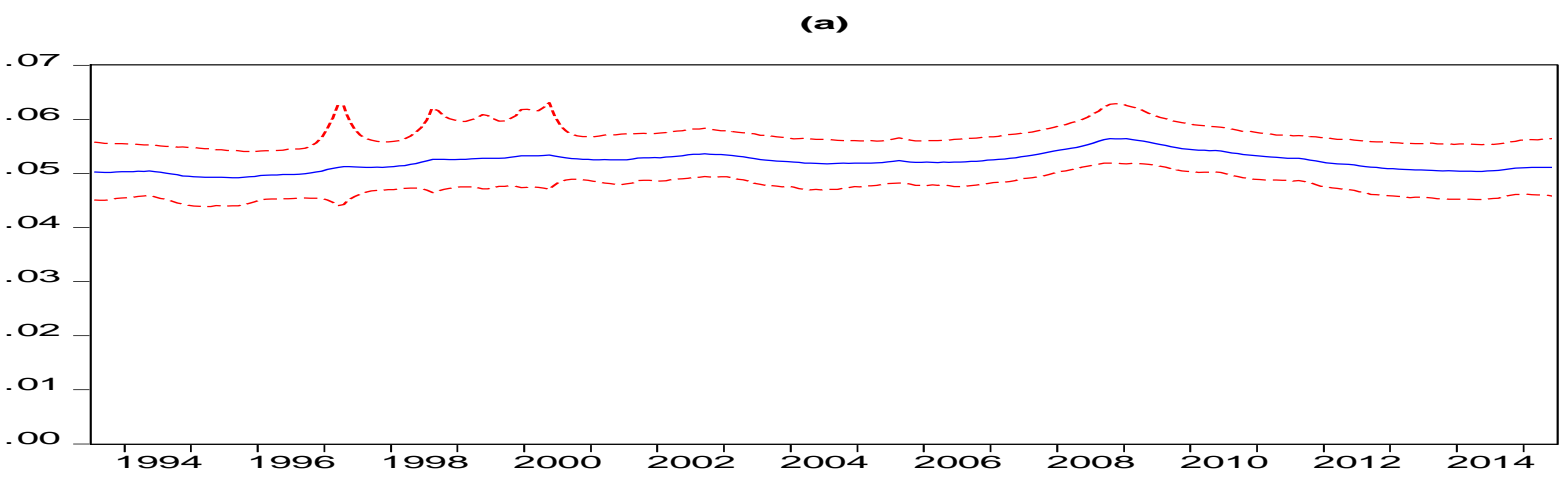

(b)

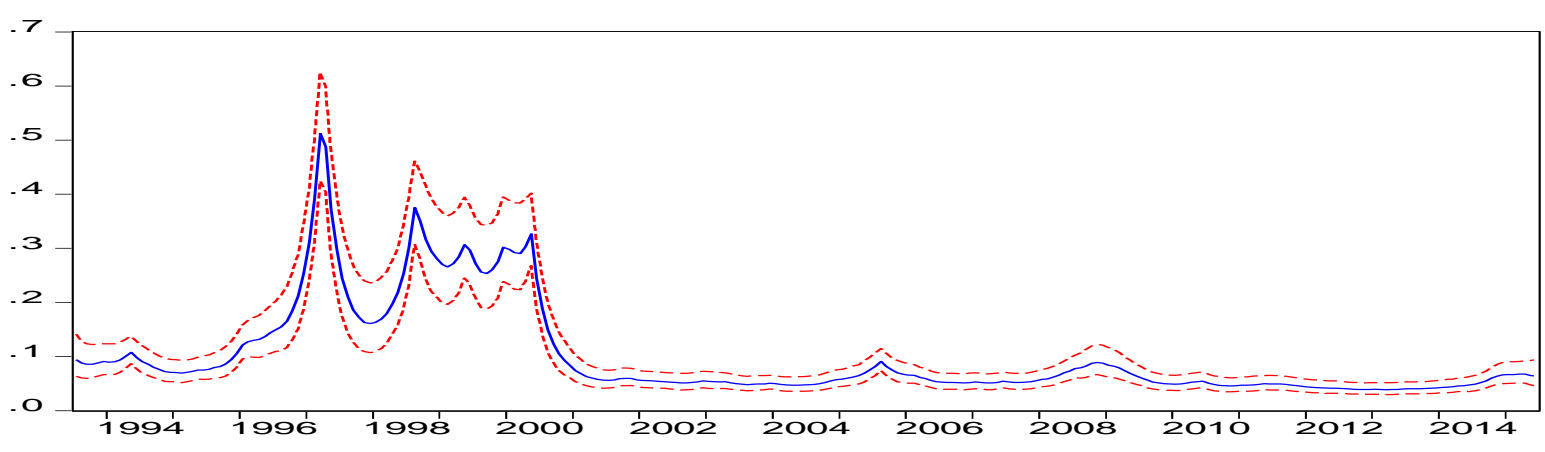

(c)

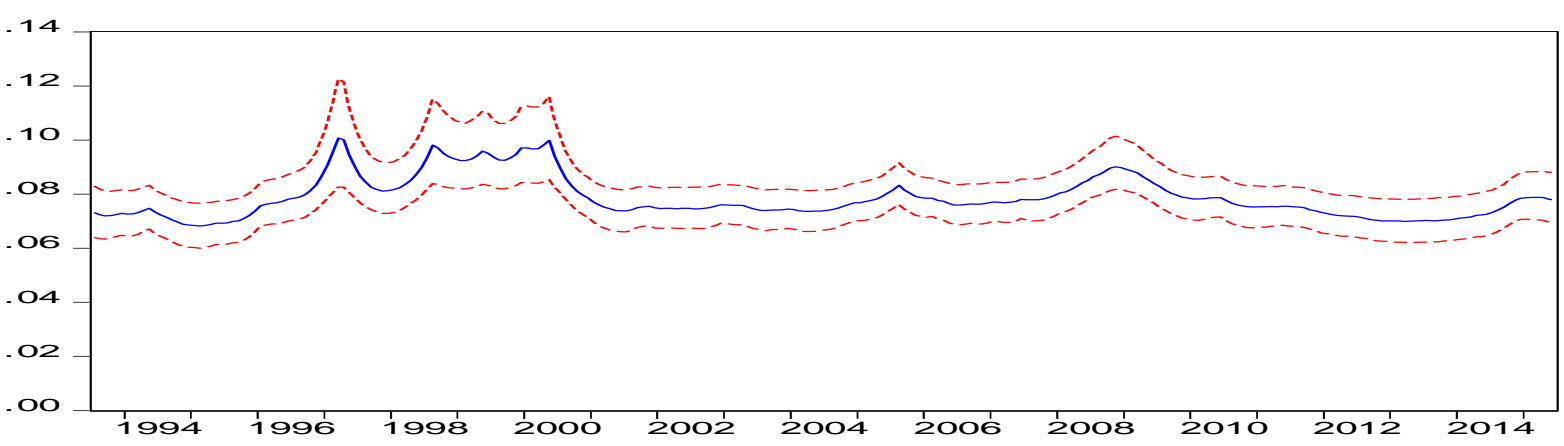

Figure 2 (a - c): Posterior mean, $16^{\text {th }}$ and 84-th percentiles of the standard deviation of (a) residual of the LnFTSE All Shares equation (b) residuals of the Oil Sector Stock equation and (c) residuals of the equation for oil price shocks

${ }^{23}$ The conversion of observations in logs is helpful here interpreting the coefficients of as elasticities. 
The changes in the effect of oil price shocks are summarised in the Figure 3. It presents the impulse responses of FTSE All shares and Oil Sector Stock to oil price shocks in four different dates of the under analysis sample. The figure 4 and 5 represents the pairwise difference between impulse responses in different dates with the 16-th and 84-th percentiles. The date chosen for the comparison are August 2001, August 2008, December 2008 and January 2015. The choice of dates is with the rationale that August 2001 was the peak period for the oil exports from the UK as the production per day was over 2.5 million barrels per day with a surplus of over 0.70 million per day after domestic consumption (EIA, 2013). The August 2008 and December 2008 were chosen as the dates before and after the Global Financial Crises. The Jan 2015 was chosen as it is the recent period and also an epoch when the UK has become a big importer of oil ${ }^{24}$.

Impulse response of Inftse

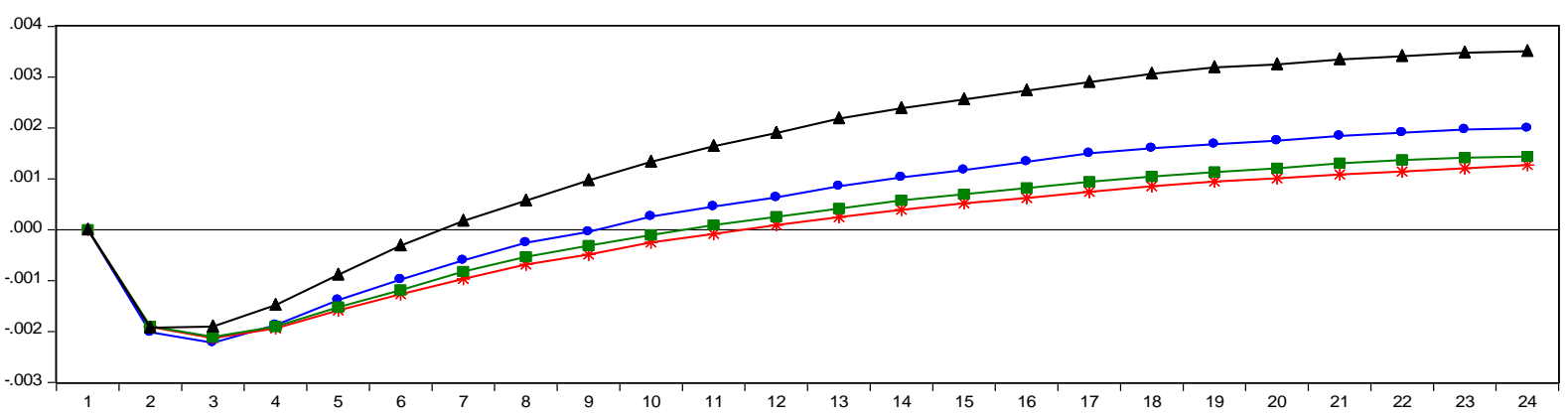

impulse response of Inoilsector

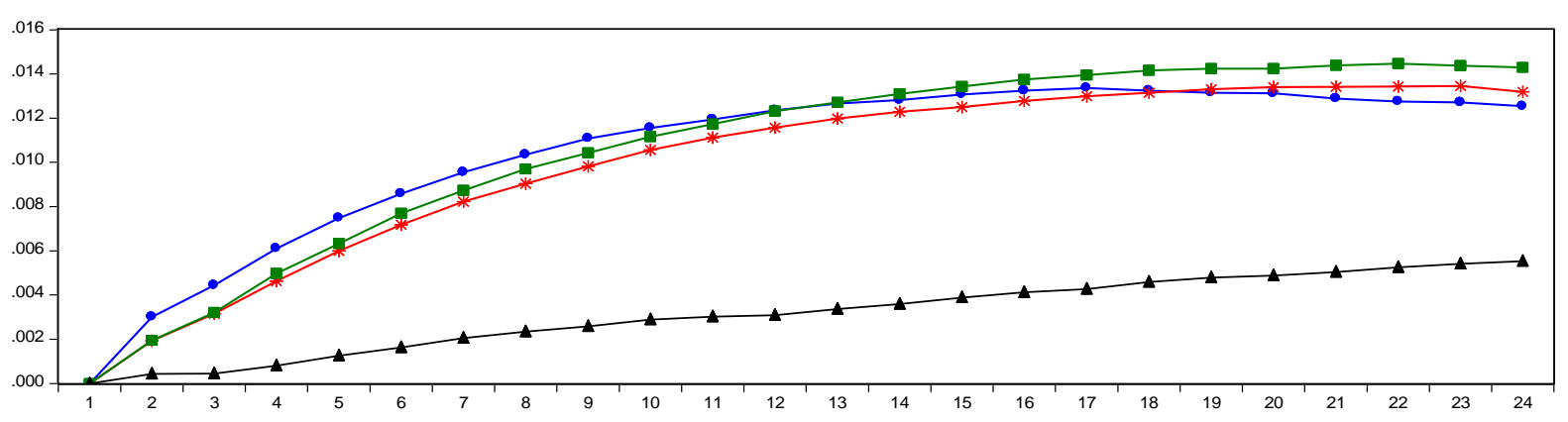

impulse response of Inoilprice

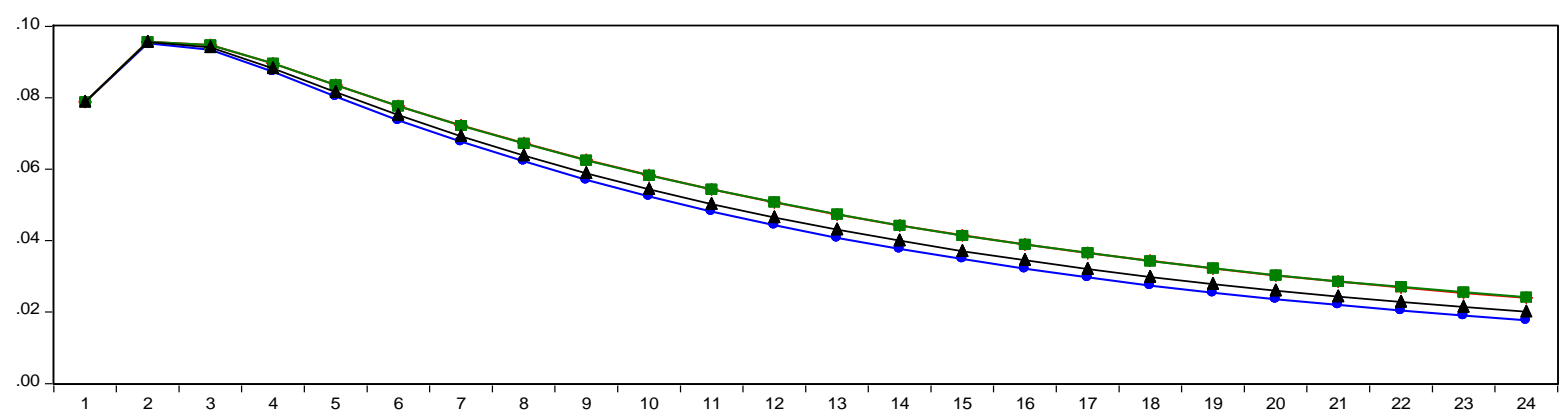

$\longrightarrow$ - Aug2001 $\longrightarrow$ * Aug 2008
$\longrightarrow$ Dec $2008 \longrightarrow$ Jan 2015

Figure 3: Oil Price Shocks in August 2001, August 2008, December 2008 \& January 2015.

${ }^{24}$ Over 12 billion tonnes in 2015Q1, for details see https:/www.gov.uk/government/uploads/system/uploads/ attachmentdata/file/533820/Section 3.pdf 
Starting with Figure 3, the results showed that the oil shock leads to a negative response from the FTSE All shares in all the periods. The intensity of the shock was the same for the first couple of periods (months) before we witnessed some differences in adjustments. It showed that the FTSE All Share which is representing the stock market on the whole recovered rather more promptly from the oil shocks in the later period when the UK has become a big importer of the oil but which is also a Post-GFC period. On the other hand, the oil shocks lead to a positive response from the Oil sector stock which persisted for several periods (month). The response of the Oil sector Stock to oil shocks was although homogeneous in the direction in all periods however it showed that the oil sector stock has become lesser responsive in the latest period. It is the Post-Global Financial Crises period and also when UK is running big imports of oils.

(A) Impulse response of Inftse

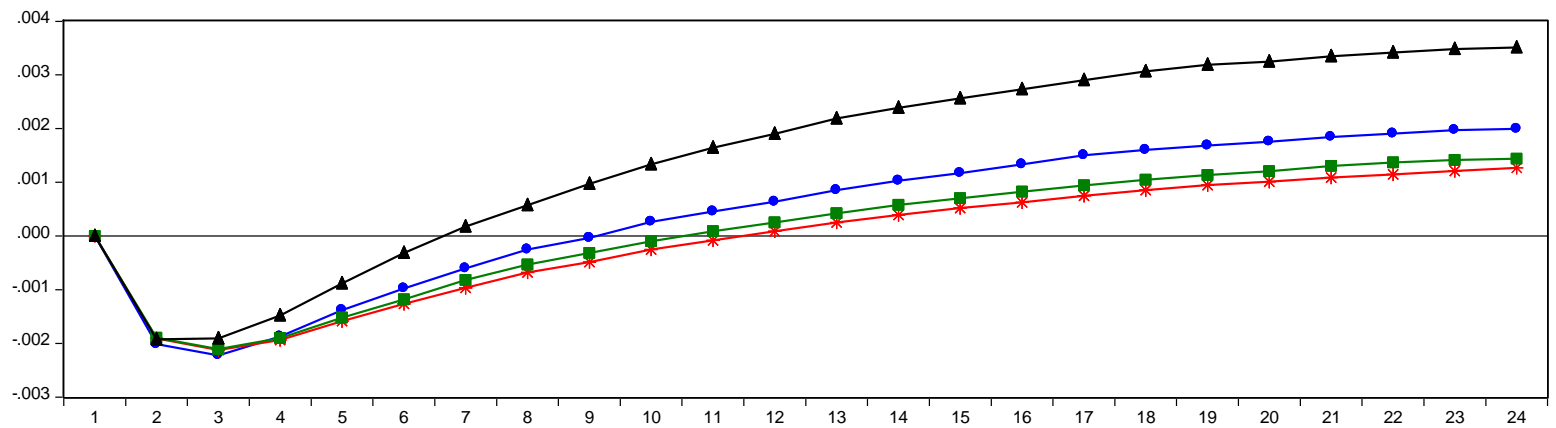

$\rightarrow$ Aug $2001 \rightarrow$ * Aug 2008

(B) Impulse response of Inftse 2001M08

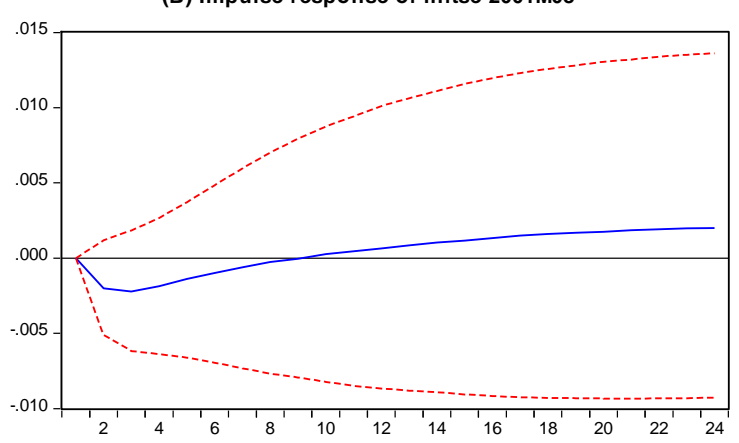

(C) Impulse response of Inftse 2008M08
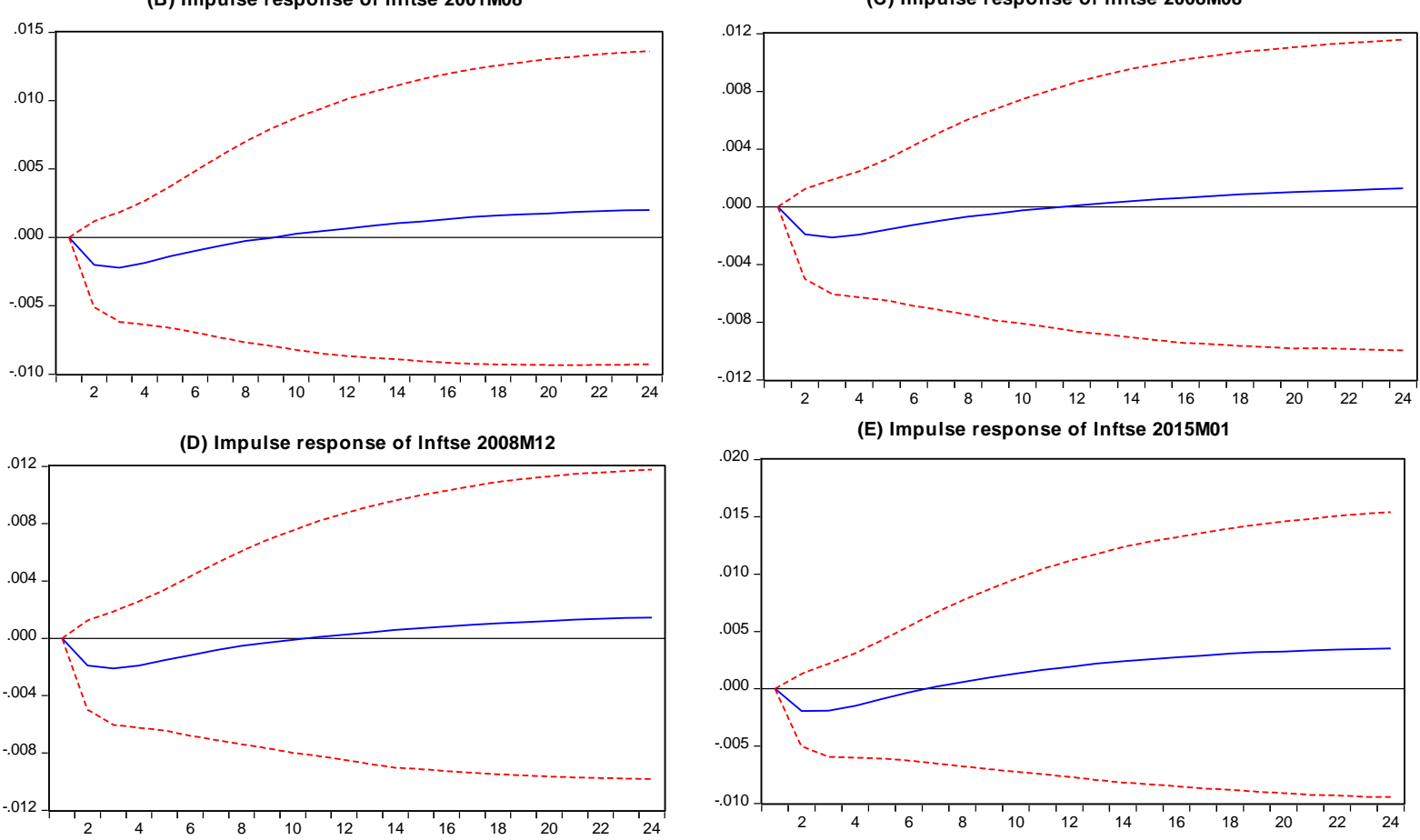

(E) Impulse response of Inftse 2015M01

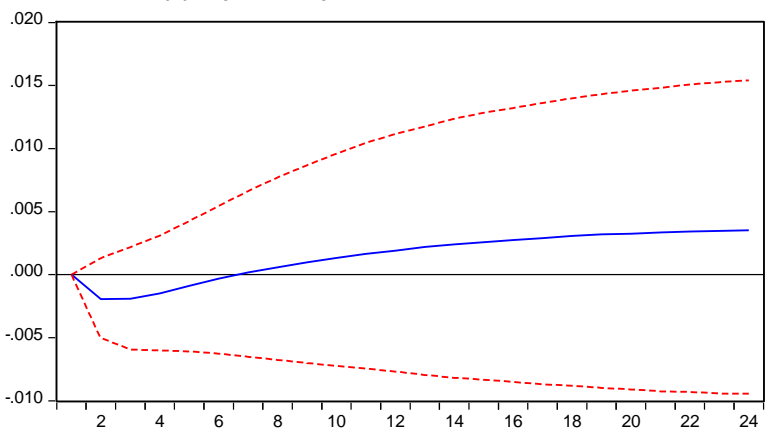

Figure 4: (a) Impulse responses of FTSE All Shares to oil Price shocks in Aug 2001, Aug 2008, Dec 2008 \& Jan 2015, (b) difference between the responses in Aug 2001 and Aug 2008 with 16-th and 84-th percentiles, (c) difference between the responses in Jan 2001 and Aug 2010 (d) difference between the responses in Aug 2008 and Aug 2010 (e) difference between responses in December 2010 and Jan 2015.

The Figure 4 showed that the responses of FTSE All Shares did vary over time which is an indication that the estimated coefficients did reflect some time variation, although the direction of response 
remained same. It also implies that the response of the stock market has been generally negative to oil shocks in all the periods when the UK was an Oil exporter and then importer and Pre as well as PostGFC. However, as we witnessed that the response of Oil Sector Stock showed a shift in the last period (Jan 2015) which has significance in terms of the Post-GFC and we see the UK as a big importer of oil in this period. It showed that the oil sector showed comparatively less pronounced positive responses to Oil price shocks. The pairwise differences in the various periods suggest that although there was some time variation in the response of stock market, there wasn't significant shift or landslide shift in the association among underlying variables of interest in different periods.

(A) Impulse response of Inoilsector

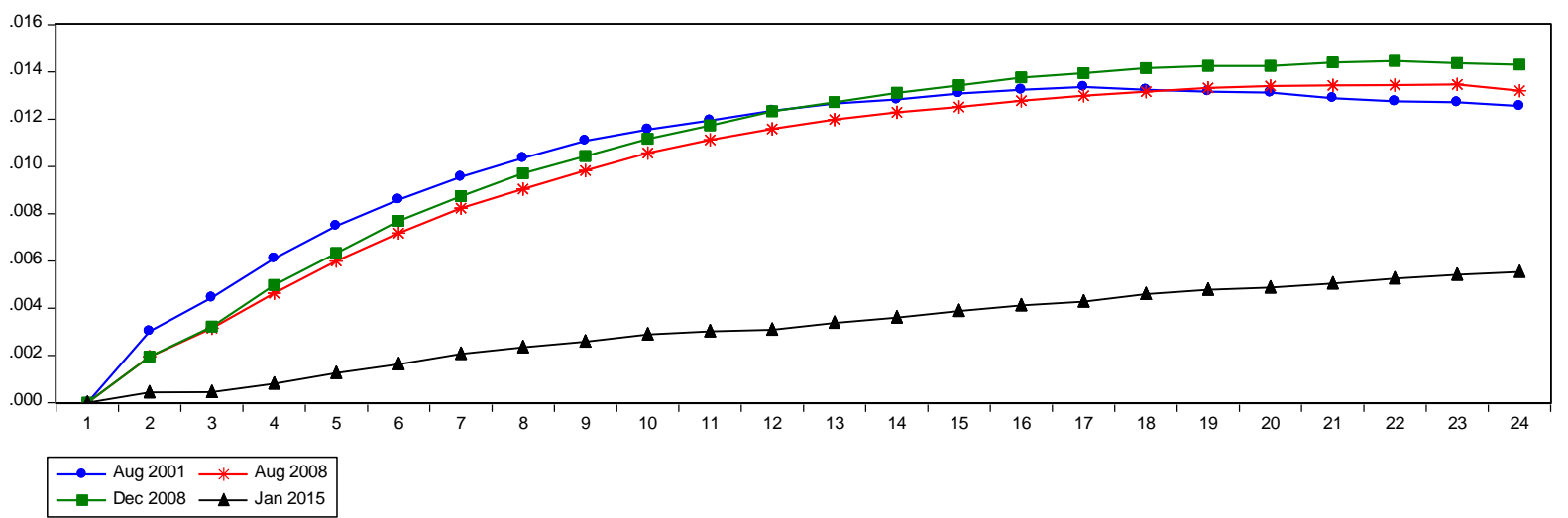

(B) Impulse response of Inoilsector 2001M08

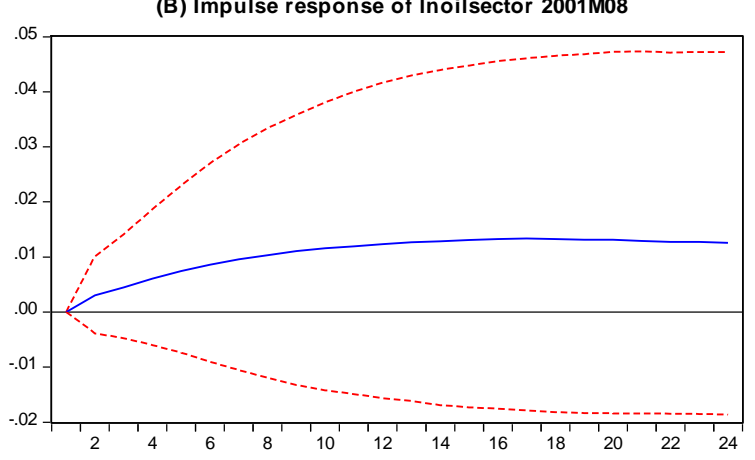

(D) Impulse response of Inoilsector 2008M12

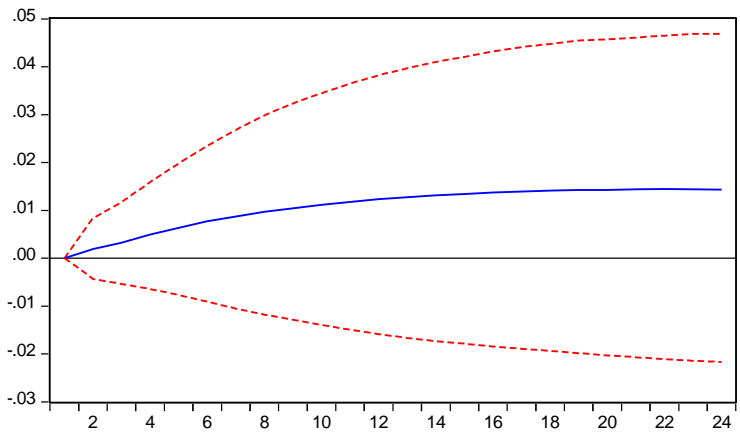

(C) Impulse response of Inoilsector 2008M08

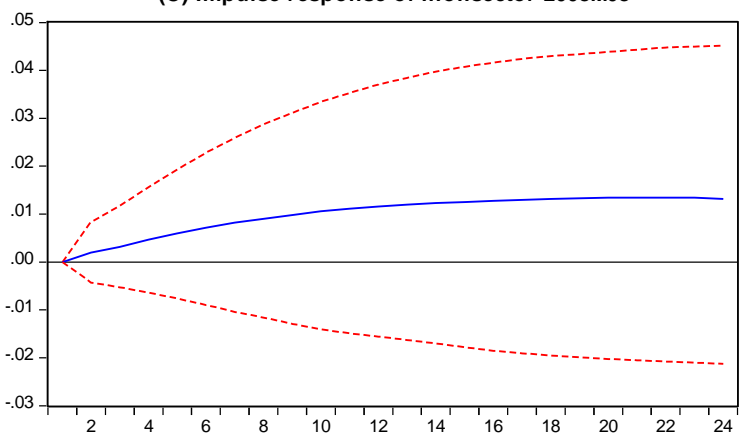

(E) Impulse response of Inoilsector 2015M01

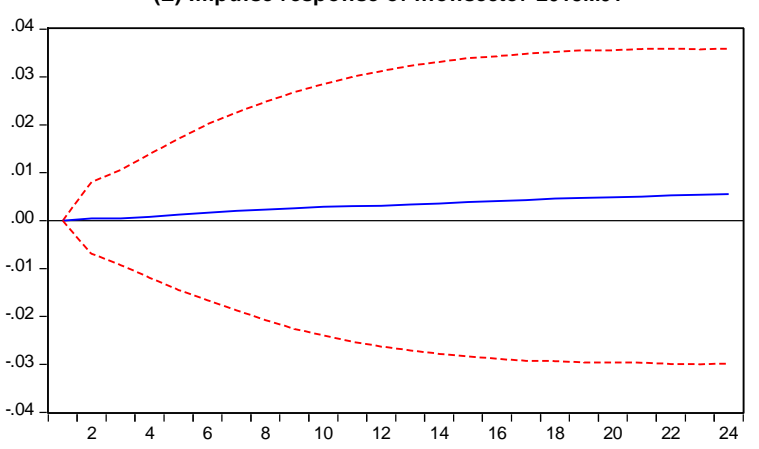

Figure 5: (a) Impulse responses of Oil Sector Stock to oil Price shocks in Aug 2001, Aug 2008, Dec 2008 \& Jan 2015, (b) difference between the responses in Aug 2001 and Aug 2008 with 16-th and 84-th percentiles, (c) difference between the responses in Jan 2001 and Aug 2010 (d) difference between the responses in Aug 2008 and Aug 2010 (e) difference between responses in December 2010 and Jan 2015.

The Figure 5 showed response of the Oil sector stock to oil shocks as well as the pairwise differences. The response as discussed earlier was symmetric in the direction of causality in all periods although there is clear evidence that the oil sector stock has become lesser responsive in the latest period. The 
pairwise differences in the various periods suggest that although there was some time variation in the response of oil sector's stock to oil shocks, however, on the whole, the relationship remained positive. The insignificant values of pairwise differences also reflect the robustness of relationship in the face of time variation.

\subsection{Discrete Break:}

After considering the period as a whole, we introduced the discrete breaks in the data series. There are studies, for instance, Sims, (1999) and Sims and Zha, (2004) which considered the discrete break in an effort to capture a limited number of switching regimes. Concomitantly, in addition to Primiceri (2005) arguments in favour of smooth and continuous drifting coefficients and heteroscedasticity innovations we introduced discrete Breaks in the analysis. It includes the UK became a net oil exporter to net oil importer and around the Global Financial Crises. Doing so will give us deeper insight, fill any caveat due to the instrument choice and provide robustness to our results.

\subsubsection{UK export periods.}

The UK has been an interesting case in this aspect as it has been shifting from net oil importer to exporter and then regaining its position as importer since 2005. The prime time in UK oil sector was 2001-2002 when the production reached to over 2.5 million barrels per day with surplus of over 0.70 million per day after domestic consumption (EIA, 2013). However, the situation changed as can been in Figure 6, it came to the point that UK has to import over 12 billion tonnes of petroleum in 2015Q1.

thousand barrels per day

3,000
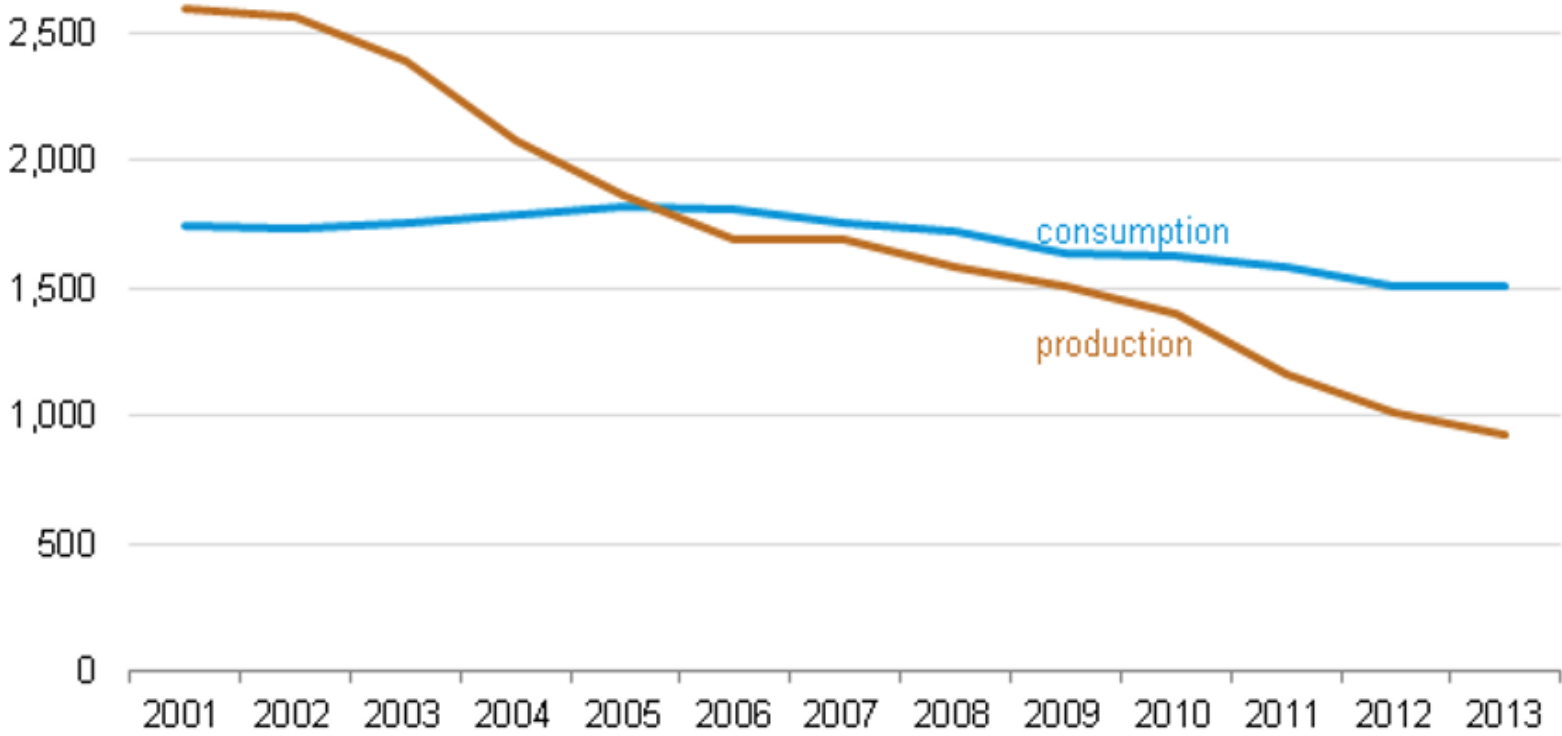

Figure 6: UK Petroleum \& other Liquids Production \& Consumption, 2001-13

Source: U.S Energy Information Administration, International Energy Statistics Data and Short-Term Energy Outlook.

Hence, we chose the August 2001 as the point of analysis. It is also a month just before the 9/11 to avoid the effects of the event. The second period chosen was Jan 2005 for comparison. We chose the 
period from Jan 1990 to Dec 2005. The impulses response analysis is presented in Figure 7 as follows:-

Impulse response of Inftse

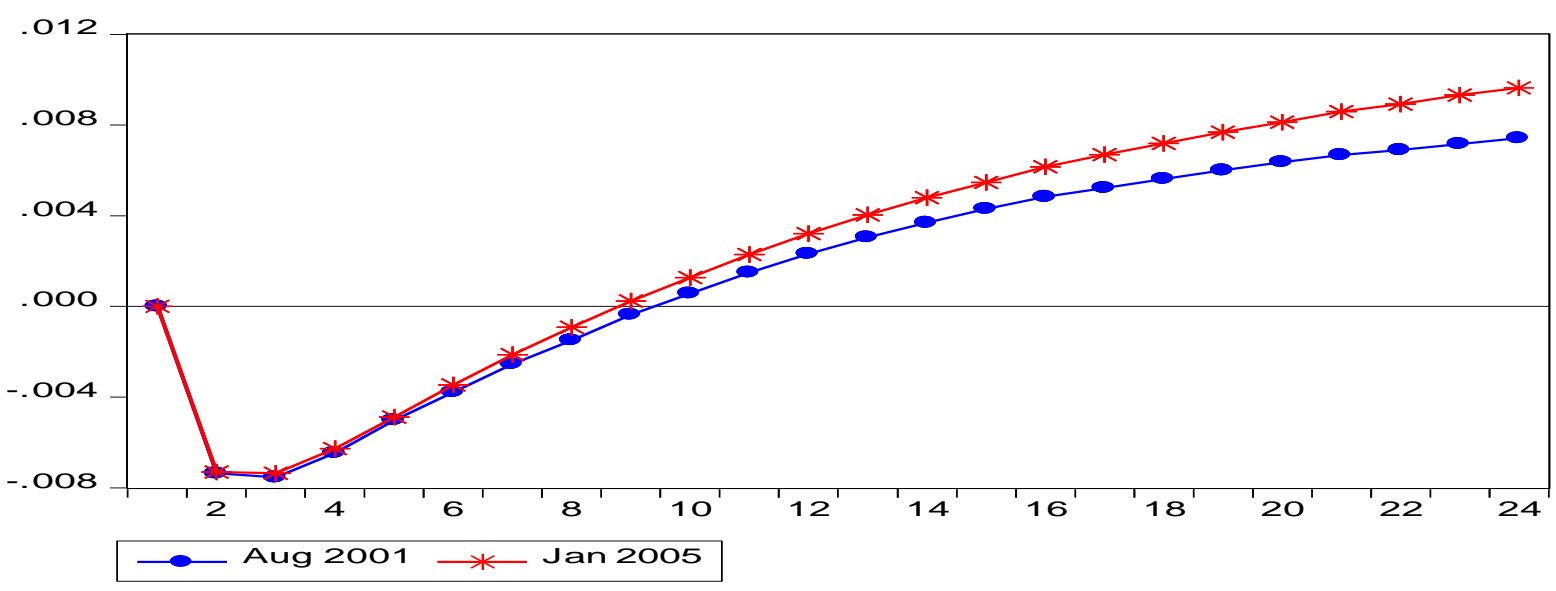

Impulse response of Inoilsector

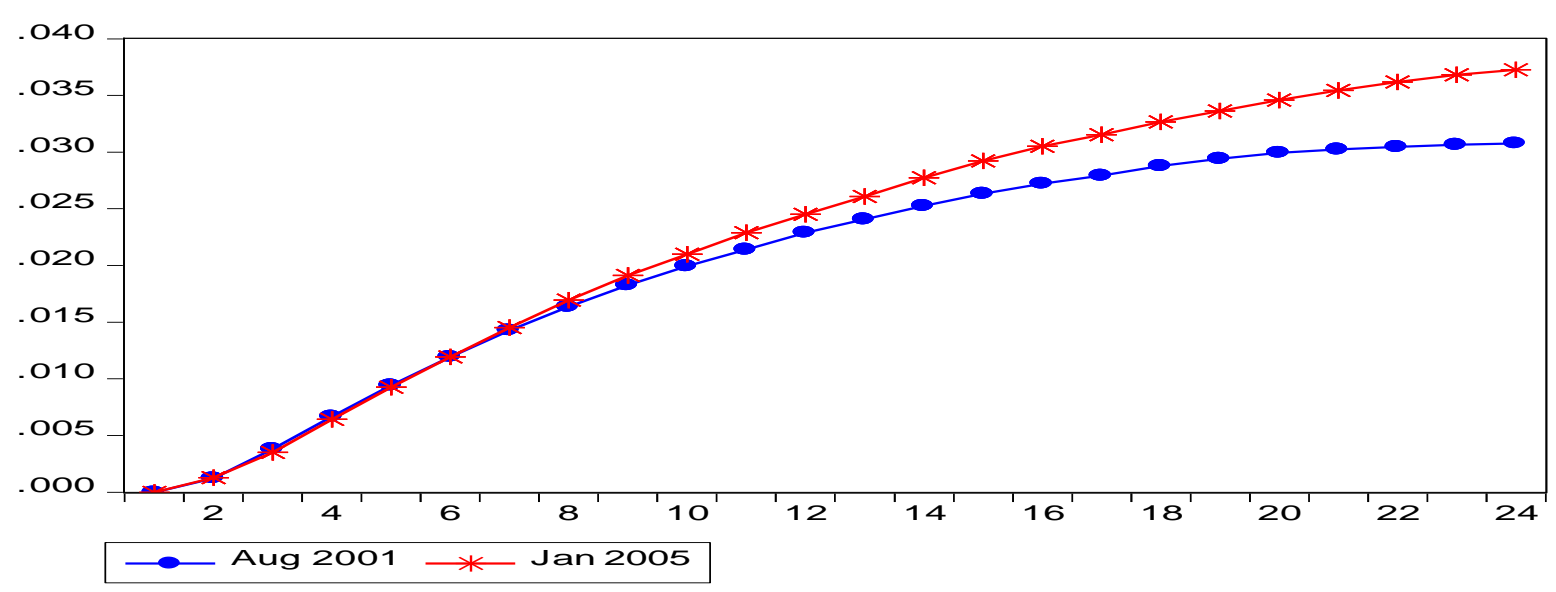

Impulse response of Inoilprice

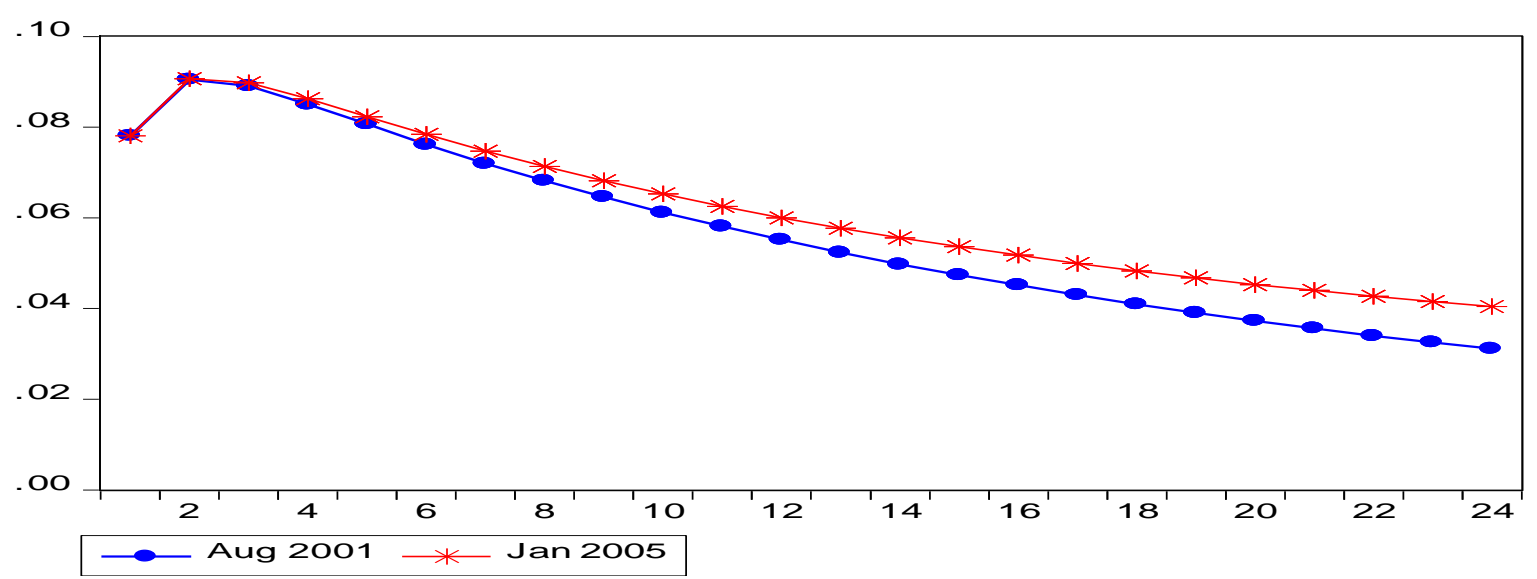

Figure 7: Impulse response of FTSE All Share, Oil Sector stock and Oil Prices to Oil Price Shocks 
The results of the TVSVAR estimated (10000 iterations of Gibbs sampler with $20 \%$ burn rate) showed that the stock market on the whole exhibited a negative response to oil shocks. However, the energy sector stock showed a positive response. The oil shock also persisted for several periods. The comparison of the two periods i.e. 2001 August when UK was net oil exporter with its historically high level of production, the response of the FTSE all share and oil sector was similar despite a little

divergence after 8 periods. It showed that in the later period the positive impact of oil shock for the energy sector companies was rather more persistent.

\subsubsection{Post GFC \& UK as Importer}

In the second phase of the discrete break, we considered the post-GFC period i.e. October 2008 to June 2015. The TVSVAR model is estimated and results of simulation are presented as follow;- 


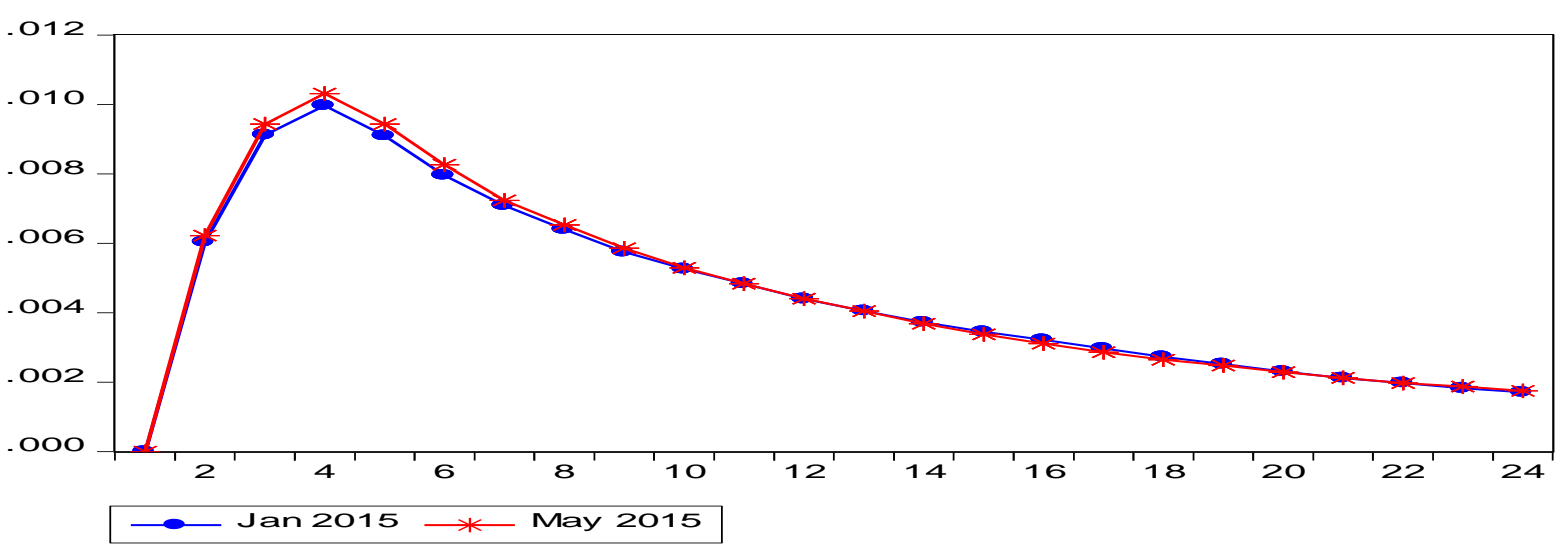

Impulse response of Inoilsector

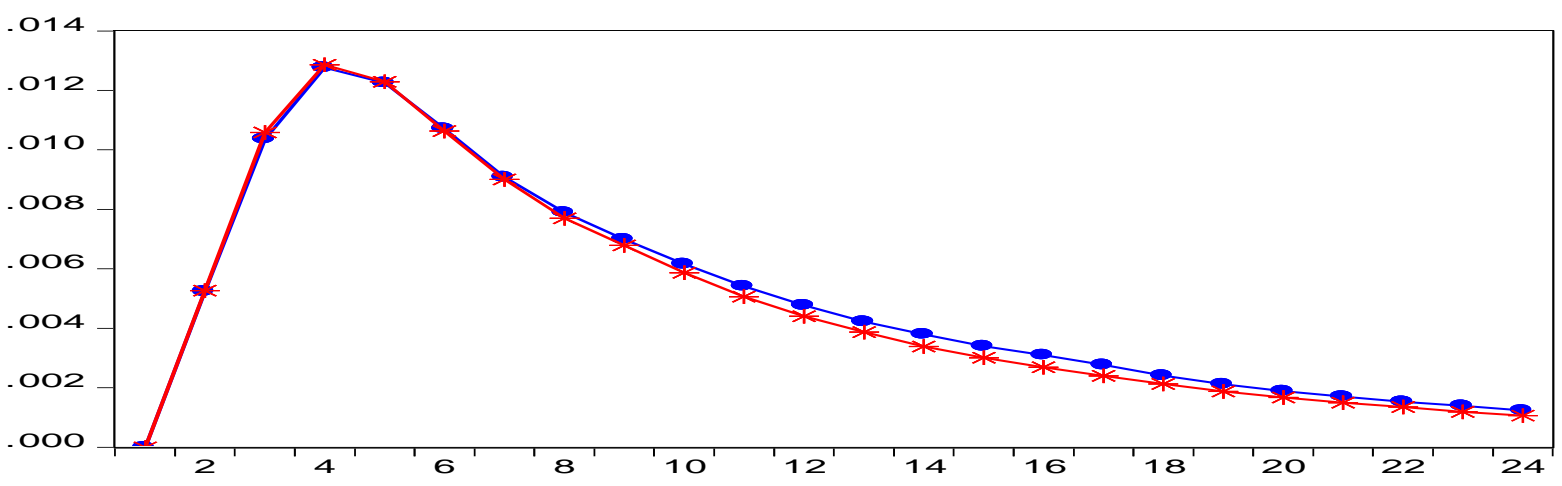

$\longrightarrow \operatorname{Jan} 2015 \longrightarrow$ May 2015

Impulse response of Inoilprice

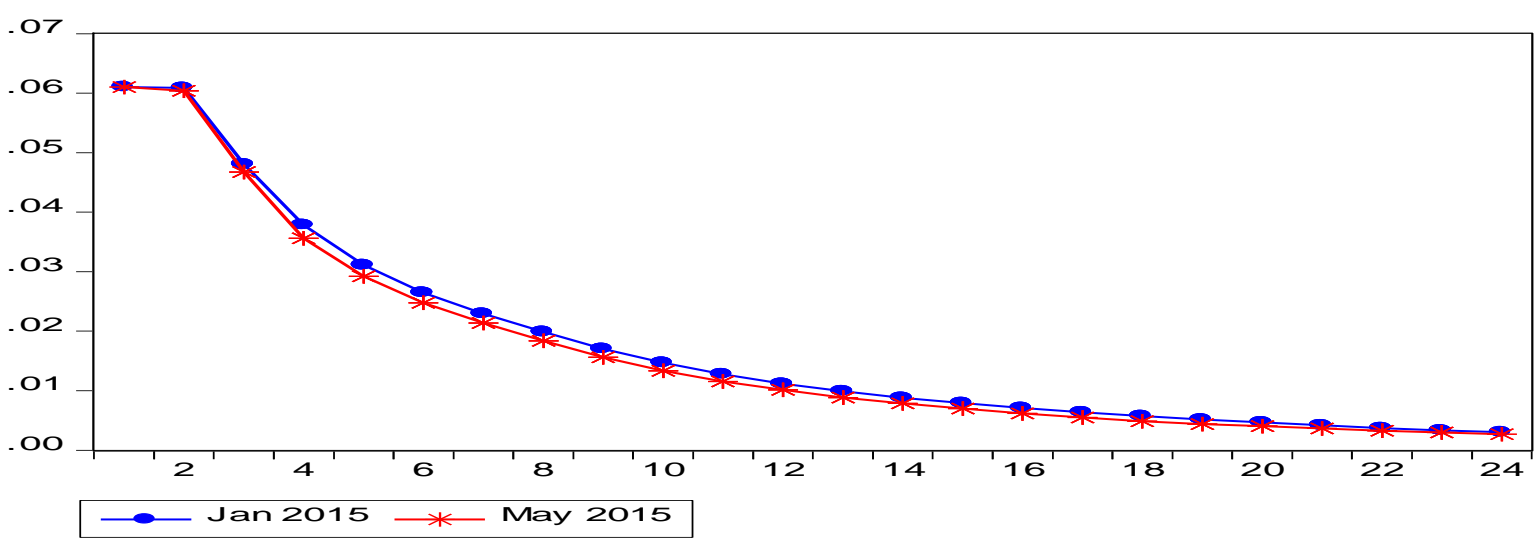

Figure 8: Impulse response of FTSE All Share, Oil Sector stock and Oil price to Shocks

The results presented in the Figure 8 were interesting and not without an element of surprise. It showed that both the stock market and energy sector stock showed a positive response to the oil price shocks in the Post-Global Financial crises. It is interesting finding in a way that although the UK has been a net oil importer and perhaps the imports are larger than ever before yet the oil price shocks are positivity affecting not only the energy section stock but the whole stock market. These findings have profound economic implications. Since the GFC, the aggregate demand in the world economy has been very weak. Hence, the oil price shocks could also emerge as the demand picks up the global economy which resultantly affects the expectations of market participants. 
There is also a methodological dimension to these results i.e. Since the sample size we used is PostGFC periods (from October 2008 onwards) hence the prior which was based on initial period of study is not based on the Pre-GFC period and also depicts a shift in the agent's behaviour which is nicely aggregated in the TVSVAR model as advocated by Primiceri (2005). However, the regime switching which was not very prominent when we did not use discrete break also became more prominent when we did. It leads us to conclude in the next section.

\section{Conclusion \& Policy Implications}

In the light of empirical results, we can hereby conclude that on the whole, the oil shock leads to a negative response from the FTSE All shares in all the periods. It showed that the FTSE All Share which is representing the whole stock market, recovered rather more promptly from the oil shocks in the Post-GFC period though the UK has become a big importer of the oil. On the other hand, the oil shocks led to a positive response from the oil sector stock, though oil sector stock has become less responsive in the latest period. It implied that in the Post-GFC period the oil price shocks are not as bad news for the UK stock market as it used to be. Whereas, the oil sector stock held its property of being a hedge against oil shocks in all periods though this feature became milder in the Post-GFC. Our study also draws conclusions in terms of discreet breaks and regime switching. An important inference one can draw is that the strategy of having a discrete break and drawing priors on the post break periods helps to gain further insight into underanalysis phenomenon. In specific to the subject treatise, it reflected a shift in the behaviour of the stock market to oil shocks from historically negative to positive. This change in the response of stock market shall be seen in the global context as the source of the oil shocks are also dynamics of aggregate demand for which we need to consider the global economic regime. In terms of policy implication and strategy for the investor, the oil sector stock has responded positively in all scenarios which provide it with the incontestable property of being a hedge against oil shocks, irrespective of the regime and empirical framework. We would terminate this inquiry here, however, as the future venue of research, further investigation of reasons which led to the shift in the stock market response to oil shocks in the Post-GFC and the earlier discussed potential implication of aggregate demand in this context could bring further insight. In this study we have been specific to the oil sector and analysed the symmetry of response to oil shocks with a comparison to the stock market, in the further research can also be extended to multi-sector analysis. However, we leave it for the excursion of future researchers.

\section{References:}

Aloui, C. Jammazi, R. (2009). The effects of crude oil shocks on stock market shifts behaviour: A regime switching approach. Energy Economics, 31, pp. 789-799.

\footnotetext{
Aloui, C. Nguyen, D. K. Njeh, H. (2012), Assessing the impacts of oil price fluctuations on stock returns in emerging markets, Economic Modelling 29, pp. 2686-2695.

Antonakakis, N. Chatziantoniou, I. Filis, G. (2017), Oil shocks and stock markets: Dynamic connectedness under the prism of recent geopolitical and economic unrest, International Review of Financial Analysis 50, pp. 1-26.
}

Arouri, M. E., Lahiani, A. Nguyen, D. K. (2011). Return and volatility transmission between world oil prices and stock markets of the GCC countries. Economic Modelling, 28(4), pp. 1815-1825.

Avdulaj, K. Barunik, J. (2015), Are benefits from oil-stocks diversification gone? New evidence from a dynamic copula and high frequency data, Energy Economics 51, pp. 31-44 
Banerjee, A., Lumsdaine, R. L., and Stock, J.H. (1992), "Recursive and Sequential Tests of the Unit Root and Trend-Break Hypothesis: Theory and International Evidence", Journal of Business and Economic Statistics, 10, pp. 271-287.

Bhunia, A. (2012). Association between Crude Price and Stock Indices: Empirical Evidence from Bombay Stock Exchange, Journal of Economics and Sustainable Development, 3(3), pp. 25-34.

Blanchard, O. J., \& Gali, J. (2007). The Macroeconomic Effects of Oil Price Shocks: Why are the 2000s so different from the 1970s? MIT Centre for Energy and Environmental Policy Research, (Working Paper No. 07-11).

Boivin, J. (2001), “The Fed's Conduct of Monetary Policy: Has It Changed and Does It Matter?", Columbia Business School, mimeo.

Boldanov, R. Degiannakis, S. Filis, G. (2016), Time-varying correlation between oil and stock market volatilities: Evidence from oil-importing and oil-exporting countries, International Review of Financial Analysis 48, pp. 209-220.

Broadstock, D., Filis, G. (2014), Oil price shocks and stock market returns: new evidence from the United States and China. Journal of International Financial Markets, Institutions and Money 33, pages 417-433.

Bouri, E. (2015), Oil volatility shocks and the stock markets of oil-importing MENA economies: A tale from the financial crisis Energy Economics 51, pp. 590-598.

Bouri, E. Awartani, B., Maghyereh, A. (2016), Crude oil prices and sectoral stock returns in Jordan around the Arab uprisings of 2010 Energy Economics 56, pp. 205-214.

Cai, X. J. Tian, S. Yuan, N. Hamori, S. (2017), Interdependence between oil and East Asian stock markets: Evidence from wavelet coherence analysis, Journal of Int. Financ. Markets Inst. Money, 48, pages 206-223

Canova, F. (2007), "Modelling and Forecasting Exchange Rates with a Bayesian Time-Varying Coefficient Model”, Journal of Economic Dynamics and Control, 17, pp. 233-261.

Chang, K.-L., Yu, S.-T., (2013). Does crude oil price play an important role in explaining stock return behavior? Energy Economics 39, pages 159-168.

Cogley, T. and T.J. SARGENT (2001), "Evolving Post-World War II U.S. Inflation Dynamics", NBER Macroeconomics Annual, MIT Press, Cambridge, Massachusetts, 331-373.

Cogley, T. (2003), "How Fast Can the New Economy Grow? A Bayesian Analysis of the Evolution of Trend Growth", University of California, Davis, mimeo.

Cogley, T. and T.J. SARGENT (2003), "Drifts and Volatilities: Monetary Policies and Outcomes in the Post WWII U.S.", New York University, mimeo.

Dargay, J. Gately, D. (1995). OECD, The imperfect price reversibility of non-transport oil demand in the OECD. Energy Economics, 17(1), pp. 59-71.

Degiannakis, S., Fillis, G. Christos, F. (2011). Dynamic correlation between stock market and oil prices: The case of oil-importing and oil exporting countries. International Review of Financial Economics, 20(3), pp. 152-164.

Demirer, R. Jategaonkar, S. P. Khalifa, A.A.A. (2015) Oil price risk exposure and the cross-section of stock returns: The case of net exporting countries, Energy Economics, 49, pp. 132-140. 
Diaz, E.M., Molero, J. C. Gracia, F.P.D. (2016), Oil price volatility and stock returns in the G7 economies, Energy Economics 54, pp. 417-430

Dickey, D. A., \& Fuller, W. A. (1979). Distribution of the estimators for autoregressive time series with a unit root. Journal of the American Statistical Association, 74(366), 427-431.

Ding, H. Kim, H. G. Park, S.Y. (2016), Crude oil and stock markets: Causal relationships in tails? Energy Economics 59, pp. 58-69

Du, L and He, Y. (2015), Extreme risk spill overs between crude oil and stock markets, Energy Economics, 51, pp. 455-465

Financial Times. (2015). FTSE 100 breaks pass 7,000 mark, Available at [http://www.ft.com/fastft/296363/ftse-100-breaks-7000-mark] accessed at (8 $8^{\text {th }}$ April 2015).

Ftiti ,Z. Guesmi,K. Abid, I. (2016), Oil price and stock market co-movement: What can we learn from time-scale approaches? International Review of Financial Analysis, 46, pp. 266-280.

Fox, A.J. (1972), Outliers in Time Series", Journal of the Royal Statistical Society, B, 34, pp. 350363.

Ghosh, S. Kanjilal, K. (2016), Co-movement of international crude oil price and Indian stock market: Evidences from nonlinear cointegration tests Energy Economics, 53 111-117

Gil-Alana, L. A. Yaya, O.S. (2014), The relationship between oil prices and the Nigerian stock market. An analysis based on fractional integration and cointegration, Energy Economics 46, pp. 328 333

Hamilton, J. D. (1983). Oil and the Macroeconomy since World War 11. Journal of Political Economy, 91(2), pp. 228,229.

Hamilton, J. D. (2005). Oil and the Macroeconomy. Palgrave Dictionary of Economics, pp. 2-16.

Hamilton, J. D. (2011). Historical Oil Shocks $1^{\text {st }}$ edition, Cambridge, Mass.: National Bureau of Economic Research.

Hamilton, J. D. (2014). The Changing Face or World Oil Markets. Working Papers: University of California.

Hammoudeh, S. M., Yuan, Y. McAleer, M. (2009). Shock and Volatility Spill overs Among Equity Sectors of the Gulf Arab Stock Markets. The Quarterly Review of Economics and Finance, 49(3), pp. 829-842.

Hatemi-J, A. Al Shayeb, A. Roca, E. (2017) The effect of oil prices on stock prices: fresh evidence from asymmetric causality tests, Applied Economics, 49 (16) , pp. 1584-1592,

Hendry, D. F. (1995). Dynamic Econometrics. Oxford: Oxford University Press.

Hooker, Mark A. (1996): "What Happened to the Oil Price Macroeconomy Relationship?," Journal of Monetary Economics, 38(2), pp. 195-213.

Huang, R. D., Masulis, R. W., \& Stoll, H. R. (1996). Energy Shocks and Financial Markets. Journal of Futures Markets, 16(1), pp. 1-36.

Huang, S. An, H. Gao, X. Hao, X. (2016), Unveiling heterogeneities of relations between the entire oil-stock interaction and its components across time scales, Energy Economics, 59, pp. 70-80. 
Inchauspe, J., Ripple, R.D., Trück, S. (2015). The dynamics of returns on renewable energy companies: a state-space approach. Energy Economics 48, pages 325-335.

Jammazi, R. Nguyen, D. K (2015) Responses of international stock markets to oil price surges: a regime-switching perspective, Applied Economics, Volume 47 (41) , pp. 4408-4422,

Jiménez-Rodríguez, R., (2015), Oil price shocks and stock markets: testing for nonlinearity, Empirical Economics 48, 1079-1102.

Jouini, J., (2013). Stock markets in GCC countries and global factors: a further investigation. Economic Modelling 31, pages 80-86.

Kang, W. Ratti, R. A. Yoon, K. H. (2015), Time-varying effect of oil market shocks on the stock market, Journal of Banking \& Finance, Volume 61, Supplement 2, Pages S150-S163

Kang, W. Ratti, R. A. Yoon, K. H. (2015), The impact of oil price shocks on the stock market return and volatility relationship, Int. Fin. Markets, Inst. and Money 34, pages 41-54.

Kaul, G., \& Jones, C. M. (1996). Oil and the Stock Markets. The Journal of Finance, 51(2), pp. 463491.

Kaul, G., \& Seyhun, N. (1990). Relative Price Variability, Real Shocks, and the Stock Market. The Journal of Finance, 45(1), pp. 479-496.

Kilian, L., 2009. Not All Oil Price Shocks Are Alike: Disentangling Demand and Supply Shocks in Crude Oil Market. American Economic Review, 93(3), pp. 1053-1069.

Kyrtsoua, C. Mikropouloua, C. Papanaa, A. (2016), Does the S\&P500 index lead the crude oil dynamics? A complexity-based approach Energy Economics 56, pp. 239-246.

Le, T.H. and Chang, Y. (2015), Effects of oil price shocks on the stock market performance: Do nature of shocks and economies matter? Energy Economics ,51, pp. 261-274

Lee, K., \& Ni, S. (2002). On the dynamic effects of oil price shocks: a study using industry level data. Journal of Monetary Economics, 49(4), pp. 823-852.

Liu, L., Ma, F. Wang, Y. (2015), Forecasting excess stock returns with crude oil market data, Energy Economics 48, pp. 316-324

Maghyereh, A. (2004). Oil Price Shocks and Emerging Stock Markets: A Generalised VAR Approach. International Journal of Applied Econometrics and Quantitative Studies, 1(2), pp. 27-40.

Malik, F., \& Ewing, B. T. (2009). Volatility transmission between oil prices and equity sector returns, International Review of Financial Analysis, 18(3), pp. 95-100.

Millard, S., \& Shakir, T. (2013). Oil shocks and the UK economy: the changing nature of shocks and impact over time. England: Bank of England: Working Paper No. 476.

Mohamed, A. (2011), Stock Returns and Oil Price Changes in Europe: A Sector Analysis, The Manchester School, Volume, 80 (2), Pages 237-261

Mork, K. A. (1989). Oil and the Macroeconomy: When Prices go up and down: An extension of Hamilton's results. Journal of Political Economy, 97(3), pp. 740-744.

Moya-Martínez, P., Ferrer-Lapeña, R., Escribano-Sotos, F. (2014). Oil price risk in the Spanish stock market: an industry perspective. Economic Modelling 37, 280-290. 
Narayan, P.K. Gupta, R. (2015), Has oil price predicted stock returns for over a century? Energy Economics 48, pp. 18-23.

Nwosa, P. I. (2014). Oil prices and stock market price in Nigeria. OPEC Energy Review, 38(1), pp. 59-74.

Pan, Z. Wang, Y. Liu, L. (2016), The relationships between petroleum and stock returns: An asymmetric dynamic equi-correlation approach, Energy Economics 56, pp. 453-463.

Park, J., \& Ratti, R. A. (2008). Oil price shocks and stock markets in the U.S. and 13 European countries. Energy Economics, 30(5), pp. 2587-2608.

Peng, C. Zhu, H. Jia, X. You, W. (2017), Stock price synchronicity to oil shocks across quantiles: Evidence from Chinese oil firms, Economic Modelling, 61, pages 248-259.

Perron, P.1989. The great crash, the oil price shock and the unit root hypothesis, Econometrica, 57, pp. 1361-1401.

Phan, D. H. B. Sharma, S.S. Narayan, P.K. (2015), Oil price and stock returns of consumers and producers of crude oil, Journal of Int. Fin. Markets, Inst. and Money, 34, 245-262

Phan, D. H. B. Sharma, S.S. Narayan, P.K. (2016), Intraday volatility interaction between the crude oil and equity markets, journal of Int. Fin. Markets, Inst. and Money 40,pages 1-13

Primiceri, G. E (2005), Time Varying Structural Vector Auto-regression and Monetary Policy, Review of Economic Studies, 72, Pages $8214-852$.

PWC (2015), The impact of lower oil prices on the UK economy, available at [https://www.pwc.co.uk/assets/pdf/ukeo-oil-prices-march-2015.pdf] accessed on 11 ${ }^{\text {th }}$ July 2016.

Ranganathan, T., Ananthakumar, U. 2010.Unit Root Test: Give It A Break, The 30th International Symposium on Forecasting, International Institute of Forecasters.

Rafiq, S. Sgro, P. Apergis, N. (2016), Asymmetric oil shocks and external balances of major oil exporting and importing countries, Energy Economics 56, pp. 42-50

Reboredo, J.C. Ugolini, A. (2016), Quantile dependence of oil price movements and stock returns, Energy Economics 54, pp 33-49.

Reiss, J. (2015), Causation, Evidence, and Inference, Routledge; 1 edition

Salisu, A. A. Isah, K. O. (2017), Revisiting the oil price and stock market nexus: A nonlinear Panel ARDL approach Economic Modelling, 66, pages 258-271.

Sadorsky, P. (1999). Oil price shocks and stock market activity. Energy Economics, 21(5), pp. 449469.

Sims, C. A. (1993), "A 9 Variable Probabilistic Macroeconomic Forecasting Model”, in J. H. Stock and M. W. Watson (Eds.), Business Cycles, Indicators and Forecasting, NBER studies in business cycles volume $28,179-214$

Sims C. A. (1999), "Drift and Breaks in Monetary Policy", Princeton University.

Sims C. A. and T. ZHA (1998), "Bayesian Methods for Dynamics Multivariate Models", International Economic Review, 39, 949-968.

Sim, N. Zhou, H., (2015). Oil prices, US stock return, and the dependence between their quantiles. Journal of Banking and Finance 55, pages 1-8. 
Smith, M. and R. Kohn (2002), "Parsimonious Covariance Matrix Estimation for Longitudinal Data", Journal of the American Statistical Association, 97, Pages 1141-1153.

Stefanova, K. (2014). Do Falling Oil Prices Foreshadow a Slump in the Stock Market in 2015? Available from [http://www.forbes.com/sites/katinastefanova/2014/12/31/do-falling-oil-pricesforeshadow-a-slump-in-the-stock-market-in-2015/] accessed at ( $8^{\text {th }}$ June 2015).

Stock J. H. and M. W. Watson (1996), "Evidence on Structural Instability in Macroeconomic Time Series Relations", Journal of Business and Economic Statistics, 14, Pages 11-30.

Therramus, T. Austin, S. (2015). Will Collapse in Oil Price Cause a Stock Market Crash? Our World, United Nation University, available online [http://ourworld.unu.edu/en/will-collapse-in-oil-pricecause-a-stock-market-crash] accessed at 30 ${ }^{\text {th }}$ November 2015.

Tsai, C. L (2015) How do U.S. stock returns respond differently to oil price shocks pre-crisis, within the financial crisis, and post-crisis? Energy Economics 50, pp. 47-62.

Tsay, R.S. (1988). Outliers, Level Shifts and Variance Changes in Time Series. Journal of Forecasting. 7, 1-20.

Uhlig, H. (1997), "Bayesian Vector Auto-regressions with Stochastic Volatility", Econometrica, 65, Pages 59-73.

Vogelsang, T and P. Perron, (1998), "Additional Tests for a Unit Root Allowing for a Break in the Trend Function at Unknown Time", International Economic Review, 39, 1073-1100.

Xu, B. (2015) Oil prices and UK industry-level stock returns, Applied Economics, 47:25, pp. 26082627 ,

Zhang, B. (2017) How do great shocks influence the correlation between oil and international stock markets?, Applied Economics, 49,15, pp. 1513-1526.

Zhu, H. Guo, Y. You, W. (2015) An empirical research of crude oil price changes and stock market in China: evidence from the structural breaks and quantile regression, Applied Economics, 47:56, 60556074 ,

Zhu, H. Guo, Y. You, W. Xu, Y. (2016), The heterogeneity dependence between crude oil price changes and industry stock market returns in China: Evidence from a quantile regression approach, Energy Economics, 55, pp. 30-41

Zhu,H. Su, X. You, W. Ren, Y. (2017) Asymmetric effects of oil price shocks on stock returns: evidence from a two-stage Markov regime-switching approach, Applied Economics, 49:25, pp. 24912507.

Zivot, E. and Andrews, K. (1992), "Further Evidence On The Great Crash, The Oil Price Shock, and The Unit Root Hypothesis", Journal of Business and Economic Statistics, 10 (10), pp. 251-70. 